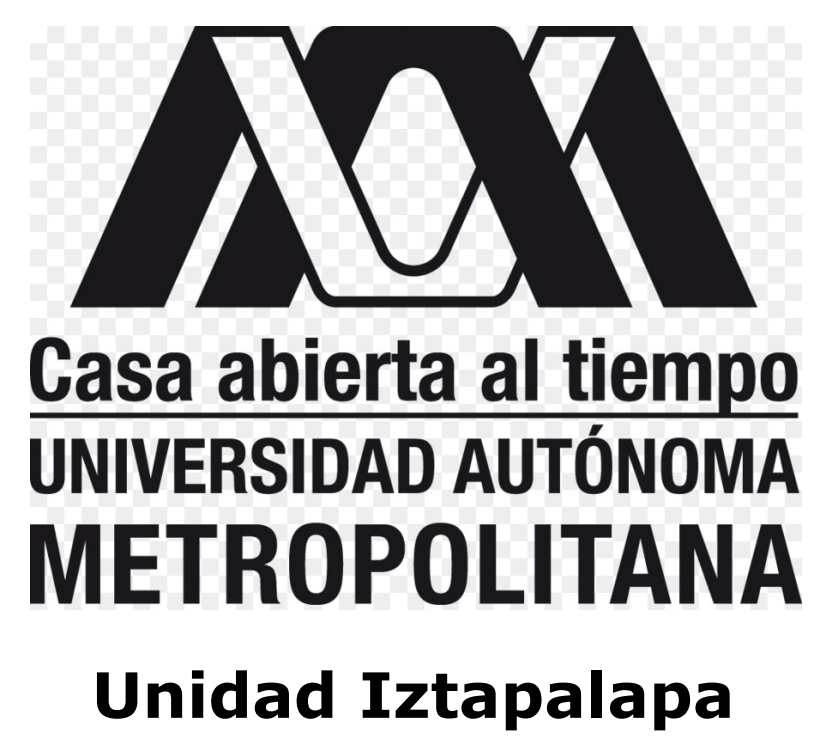

\title{
El participio en construcciones pasivas y resultativas del español
}

IDÓNEA COMUNICACIÓN DE RESULTADOS

QUE PARA OBTENER EL TÍTULO DE

MAESTRA EN HUMANIDADES

(LÍNEA DE LINGÜÍSTICA)

PRESENTA:

\section{Rocío HeRnÁNDEz LóPEZ}

Matrícula: 2163800657

Asesor: Dr. José Lema Labadie 


\section{Contenido}

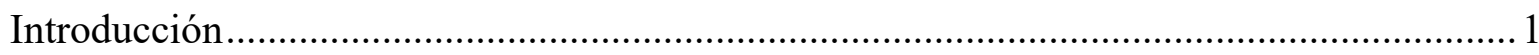

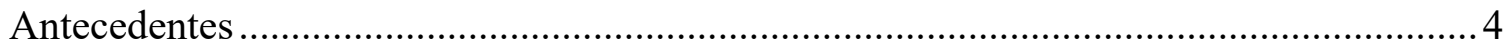

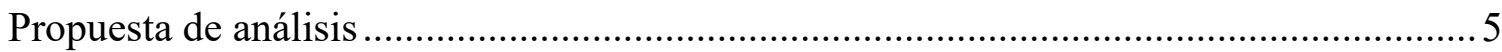

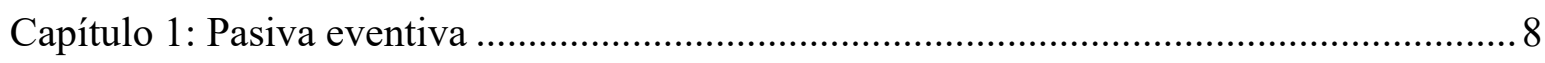

¿Qué es una construcción pasiva?................................................................................. 8

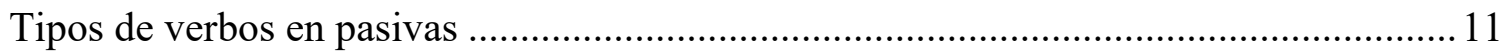

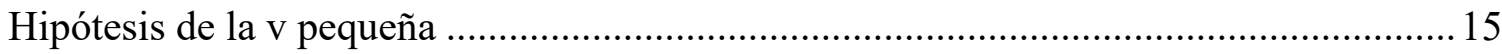

Estructura y características de la pasiva: sobre ser y el participio ....................................24

Derivación de una pasiva: Frase participial ...............................................................26

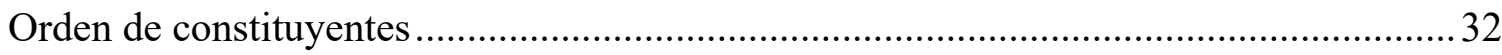

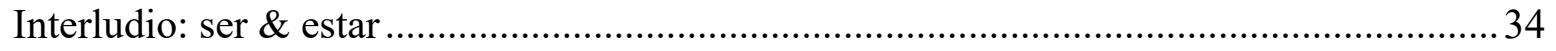

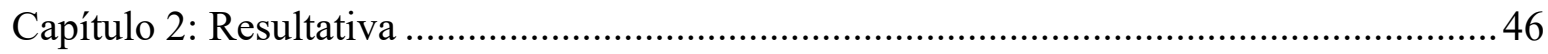

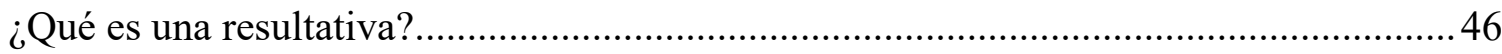

Tipos de verbos en resultativas en español ....................................................................5

Ejemplos de resultativas en español ...........................................................................53

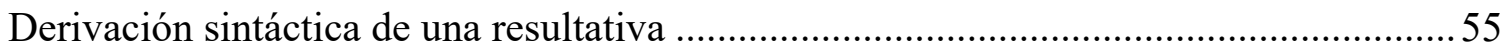

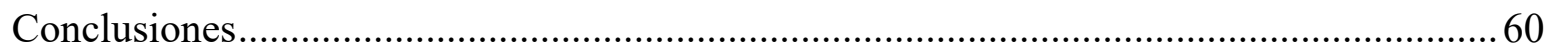

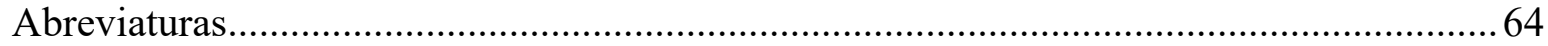

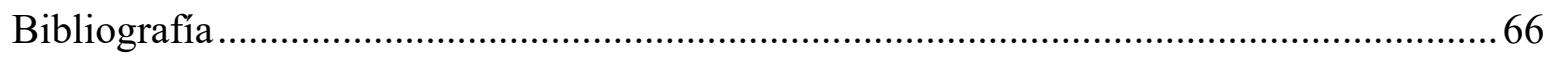

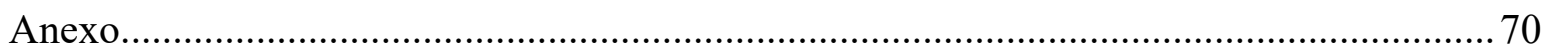




\section{Introducción}

El objetivo de esta idónea comunicación de resultados será presentar el análisis sintáctico de aquellos participios del español que coocurren en estructuras con ser/estar y que pueden tener distintas interpretaciones, a saber, la de pasiva eventiva, resultativa estativa ${ }^{1}$ y adjetival. El estudio se llevará a cabo con base en algunos postulados del programa minimalista de Chomsky y el modelo de descomposición léxica iniciado por Hale y Keyser (1993) y Marantz (1997). ${ }^{2}$

Obsérvense las siguientes oraciones:

(1) Las luces son apagadas a las 11 todos los días por el portero.

(2) El aire acondicionado está apagado.

(3) Su sonrisa es apagada.

(4) Miguel está apagado hoy, ¿no te parece?

Las distintas interpretaciones se pueden resumir de la siguiente manera: (1) implica un proceso y puede presentar un argumento agentivo explícito o implícito y un tema en posición de sujeto, i.e. es una pasiva perifrástica, dinámica, de acción o eventiva; en (2) el participio denota un estado, resultante de un proceso previo, i.e. un estado secundario o

\footnotetext{
${ }^{1}$ También llamada pasiva resultativa.

${ }^{2}$ Desarrollado con detalle para el español en Cuervo (2003). Básicamente consiste en la postulación de elementos verbalizadores dentro de las frases verbales que dan lugar a distintos tipos de verbos. Hale y Keyser fueron los primeros en intentar deshacerse de la teoría de la estructura temática (Harley, 2011), lo cual surge dadas las asimetrías en la distribución de papeles temáticos para sujetos y objetos (Cuervo, 2003). Hale y Keyser vincularon la cuestión del número de papeles temáticos con una cuestión morfológica: los verbos inergativos en muchas lenguas muestran señales de que su derivación involucra un nominal que denota un evento y un verbo "ligero" agentivo (generalmente glosado como "do"). De ahí propusieron las derivaciones de, prácticamente, todo tipo de verbo.
} 
derivado, ya que se trata de la consecuencia de una acción +/-agentiva, +/-volitiva; ${ }^{3}$ en (3) se expresa un estado que puede ser inherente (siempre ha sido así, desde su primera sonrisa) o +permanente (si bien no nació así, el estado de su sonrisa permanece por largo tiempo); por su parte, (4) implica un estado -permanente, es decir, estar parece delimitar la extensión temporal de éste (sólo hoy se encuentra así). ${ }^{4}$ Puesto que (1) y (2) implican un proceso, podríamos decir que estos participios son verbos, mientras que los de (3) y (4) parecen adjetivos.

Su propio nombre lo dice todo: del latín participium, de particeps ('que comparte o participa'), compuesto de pars ('parte') y capiō ('tomar, captar, capturar'), el participio se conoce como una forma no personal del verbo que posee morfemas de género y número, en español por lo menos, y en esta lengua, como en inglés, por ejemplo, son generalmente considerados dentro de las categorías verbal o adjetival. En este estudio, sin embargo, se propondrá la derivación a partir de raíces, más que de categorías y se enfatizará la interpretación semántica sobre la clase de palabra resultante.

Continuando con la historia, el participio de perfecto pasivo es la única forma de participio que pasó del latín al español. En la tradición se conoce como participio pasado o participio pasivo, pues ocurre en construcciones activas como "ha pintado" y pasivas como “es/fue/ha sido/será pintado”. Los participios de perfecto del latín tenían básicamente sólo carácter pasivo y expresan anterioridad (o perfección); por ejemplo, scriptvm est significa ‘fue/ha sido escrito' — aunque, en realidad, dichos significados se encuentran en mayor o menor grado dependiendo del tipo de verbo- Con verbos transitivos activos, las formas

\footnotetext{
${ }^{3}$ Pensemos que alguien efectivamente pudo haber apagado el aire acondicionado o que se desenchufó porque alguien se tropezó con el cable sin querer.

${ }^{4}$ También se puede hablar de propiedades a nivel de individuo (Individual Level) para (3) y a nivel de estadio (Stage Level) para (4).
} 
del latín pasaron a ser las formas participiales típicas del español (y otras lenguas, por supuesto). Por ejemplo, amatus pasó a ser ‘amado'; scriptus, 'escrito', etcétera.

Una perífrasis de participio y verbo copulativo en latín (como scriptvm est, scriptvm erat, etc.) tiene los siguientes significados:

a) Estado alcanzado: estado del sujeto como resultado de una acción anterior. Entonces, es como las construcciones participio + estar del español. Así, scriptvm est, fuit, erit... significa 'está, estuvo, estará... escrito'.

b) Acción pasiva: se forma solamente con las formas est, erat, erit del verbo auxiliar, pero el significado es de perfecto: scriptvm est equivale a 'fue o ha sido escrito', aunque el auxiliar no sea fuit, en este caso. ${ }^{5}$

Tenemos, entonces, un participio con un sentido de perfección, que no pasó como tal a la lengua española. Se perdió ese significado de temporalidad y el sufijo - $d$ - quedó semánticamente vacío. En construcciones como Mario ha pintado la pared existe el sentido de perfección puesto que el auxiliar "haber" se lo agrega y la temporalidad ${ }^{6}$ está presente: ha pintado implica que el sujeto comenzó a pintar y puede significar que terminó o no de hacerlo. Ahora bien, ¿por qué semánticamente vacío? Porque aparece en construcciones donde claramente adquiere propiedades de (a) nominal, (b) verbo o (c) adjetivo, donde no se puede mantener que el sentido de perfección esté en la propia forma participial.

(a) "Lo bailado nadie me lo quita", "Está padre la cantada", "Le pusieron una regañada de aquellas", "Es un aguado/aburrido", "Mario está de pesado".

\footnotetext{
${ }^{5}$ El pluscuamperfecto pasivo sería scriptvm erat 'había sido escrito'; mientras que un futuro perfecto pasivo, scriptvm erit 'habrá sido escrito'. Toda esta información ha sido tomada de Bassols de Climent (2015 [1956]), p. $247, \S 390$ y p. $228, \S 365$.

${ }^{6}$ A veces también señalado como aspecto perfecto.
} 
(b) "Ya había terminado cuando me hablaste", "El piso es pulido (todos los viernes)", "Consumido el hombre (por sus preocupaciones), terminó enloquecido".

(c) "la torcida mente de aquel hombre", "árbol caído", "desinformado", "maleducada", "indisciplinadas", "el piso está pulido", "la rama está torcida" "ella siempre ha sido organizada".

Cómo se mencionó en un principio, en la presente investigación se analizarán aquellas formas participiales que coocurran en estructuras con ser y estar y que adquieren tres lecturas diferentes: ya sea que impliquen un proceso, como los ejemplos "El piso es pulido todos los viernes" en (b) o "el piso está pulido" en (c), o no, como en "ella siempre ha sido organizada".

\section{Antecedentes}

En su artículo “On Resultative Past Participles in Spanish”, Bosque (2014: 42-43) menciona varios estudios previos acerca de los participios, de los cuales tres se relacionan con los puntos a tratar en la presente investigación. Éstos son:

(i) Se ha propuesto que los participios son de diferentes tipos en general o variedades de estas dos clases de palabras. Embick (2004) ${ }^{7}$ y Kratzer (2000) los analizan en construcciones pasivas eventivas y resultativas.

\footnotetext{
${ }^{7}$ En las primeras páginas de su estudio sobre pasivas resultativas en inglés, Embick (2004) caracteriza la interpretación de formas participiales del inglés considerándolas en las siguientes construcciones: (i) Pasivas eventivas: This box was emptied (by the dustman). ='Esta caja fue vaciada por el basurero'; (ii) Resultativas: This box was emptied. $=$ La caja estaba en un estado de haber sido vaciada = 'Esta caja (ya) estaba vaciada'. (iii) Estativas: This box was empty. (ya no es participio, sino adjetivo) = 'Esta caja estaba vacía'.
} 
(ii) Muchos gramáticos formales parecen estar de acuerdo en que las variedades de participios se derivan de capas verbales (relacionadas con aspecto, voz, el evento mismo o su resultado) (Véanse Embick, 2004 y McIntyre, 2013). La cuestión es que sigue habiendo controversia respecto a qué capas están involucradas en cada lectura de un participio y cómo están dispuestas estas proyecciones exactamente. Además, la cuestión sobre qué tipos de participios específicos se derivan directamente de raíces verbales, frente a considerar la derivación como series de proyecciones en una estructura sintáctica jerarquizada, también sigue en debate.

(iii) Los participios se consideran formas pasivas que pueden ser vistas como resultados de operaciones en la estructura argumental (absorción de caso, externalización de papel temático), ya sea a partir de los análisis con base en la teoría de rección y ligamiento, o desde la perspectiva de estructuras sintácticas complejas que involucran proyecciones de voz (Frase Voz). Las proyecciones aspectuales quizás se ubiquen por encima de aquellas cuyo núcleo es voz. En las lenguas romances, como los participios concuerdan en género y número con su argumento interno, se supone alguna proyección asociada con rasgos phi probablemente ubicada en la parte superior de la estructura.

\section{Propuesta de análisis}

El tratamiento de los participios en esta comunicación se enfoca específicamente en el análisis de las construcciones pasivas eventivas y resultativas estativas con el fin de identificar qué elementos dentro de la estructura sintáctica están involucrados en la 
derivación de los participios que aparecen en ellas. Igualmente, buscará describir cómo se efectúa la concordancia de género y número, así como explicar el papel de un rasgo aspectual en la interpretación de dichas construcciones.

Mi propuesta de análisis consiste en considerar que los participios tienen una estructura autónoma, la Frase Participial, que se encuentra incrustada en la frase v pequeña. Dentro de esta estructura se dan procesos de derivación morfológica y concordancia del sufijo con el argumento interno. Ésta podría incluso ser considerada como una "etapa o fase" ${ }^{8}$ de la derivación con una interpretación semántica propia que queda lista para "pasar" a la siguiente fase: el dominio de ser o estar como auxiliares en dichas estructuras.

En el primer capítulo se analizarán las construcciones pasivas eventivas, donde trataré cuestiones como la derivación a partir de un elemento verbalizador de tipo $\mathrm{v}_{\mathrm{DO}}-$ cabeza funcional que introduce un argumento externo agentivo como su especificador-, excluyendo la posibilidad de que estos participios puedan derivarse a partir de $\mathrm{v}_{\mathrm{GO}}$ —cabeza que introduce un único argumento tema-, y, al mismo tiempo, se explicará con más detalle la propuesta de Hale y Keyser (1993), Marantz (1997) y el análisis de Cuervo (2003) con respecto a estos elementos verbalizadores y se explorarán algunos puntos respecto al orden de constituyentes. ${ }^{9}$ Habrá un interludio donde se explique en términos generales las diferencias entre ser y estar, elementos en los que radica la diferencia de interpretación de una pasiva o resultativa. En el segundo capítulo se estudiarán las

\footnotetext{
${ }^{8}$ Fase en el sentido de que, una vez dada la derivación del participio, en las pasivas y resultativas la interpretación semántica de un proceso implícito surge en esta primera fase. Dicha interpretación quedará presente en las pasivas y en las resultativas dará pie a que, aunque toda la oración se interprete como un estado, se mantendrá el sentido de proceso debido a cómo se derivó el participio en un principio. También con la idea de que la interpretación de predicados ocurre de manera cíclica y las fases hacen más sencilla la computación.

${ }^{9}$ Inversión de sujeto como en "Fueron organizados todos los alumnos por el profesor para formar equipos".
} 
construcciones resultativas de tipo estativo, explicando un posible análisis de cómo surge la interpretación de estado resultante a partir del participio, también derivado de $\mathrm{v}_{\mathrm{DO}}$, así como del papel que juega estar y el lugar que ocupa en la estructura. Reitero que sólo aquellos participios que puedan adquirir las cuatro lecturas serán considerados, con el fin de dar cuenta de la manera en que se derivan y qué elementos entran en juego al momento de su interpretación semántica. 


\section{Capítulo 1: Pasiva eventiva}

\section{¿Qué es una construcción pasiva?}

Chomsky, en Syntactic Structures (1957: 78), ${ }^{10}$ presenta una regla llamada Transformación Pasiva, según la cual una estrcutura pasiva tiene una correlación directa con una activa:

(1) $\mathrm{NP}-\mathrm{Aux}-\mathrm{V}-\mathrm{NP}_{2} \rightarrow \mathrm{NP}_{2}-$ Aux + be + en $-\mathrm{V}-$ by $+\mathrm{NP}_{1}$

The man will hit the ball $\rightarrow$ The ball will be hit by the man

Con sus ejemplos de estructuras en inglés, Chomsky propuso que una gramática simple de esta lengua debería contener una estructura de frase y una parte transformacional. La primera consistiría en oraciones simples, declarativas, activas y todos los demás tipos de oraciones podrían ser descritas como transformaciones (Chomsky, 1957: 80). Tarald Taraldsen en su artículo "On by-Passive and why unaccusatives don't passivize" (2015) explica que en Aspects (1965), Chomsky considera by passive (by $+\mathrm{NP}_{1}$ ) como un adverbio de manera y su presencia justificaría el hecho de prevenir que se aplique una transformación pasiva en verbos que no aceptan este adverbio, como pesar en "La calabaza pesó 100 kilos" o parecerse en "Juan se parece a su mamá". Taraldsen agrega que los sujetos de estos dos verbos en los ejemplos mostrados son no agentivos, así que se puede asumir que el by passive en (1) es un adverbio de tipo agentivo. Como los verbos inacusativos como caer, etc. tampoco tienen sujetos agentivos, entonces no aparecerán en

\footnotetext{
${ }^{10}$ El ejemplo en (1) fue tomado de Taraldsen (2015: 255).
} 
construcciones pasivas (en el modelo de Chomsky, 1965, se diría que no pueden pasar por una transformación pasiva).

Taraldsen propone que si la descripción de la pasiva en Aspects se incorpora a un marco teórico donde la segunda FN en (1) deba moverse a una posición vacía de sujeto y donde el único argumento de un verbo inacusativo se origina en la Frase Verbal, la transformación pasiva tendría una estructura similar a la de una oración con un verbo inacusativo, en otras palabras, se parecen porque ambas estructuras carecen de sujetos agentes. Además, recordemos que la frase by $N P$ (por FN) no siempre es necesaria en una pasiva.

(2) La casa fue construida en 1995 (?por los albañiles).

(3) El gato desapareció en 1995(*por mi primo).

(4) *El gato fue desaparecido. ${ }^{11}$

Entonces, no basta con definir una pasiva como la "asociación inusual de los roles semánticos y las funciones sintácticas: el paciente semántico es el sujeto sintáctico de la oración, en oposición a la voz activa donde el agente semántico es el sujeto sintáctico” (Haspelmath y Sims, 2010: 85, 237), puesto que estaríamos situándola todavía dentro del modelo de transformaciones de hace más de cuarenta años. Siguiendo la línea de los modelos teóricos actuales como el descrito por Taraldsen, es posible definirla como una construcción en la cual el verbo, que denotará un proceso y cuyo argumento interno es un Tema, se deriva por medio de un elemento verbalizador, el cual a la vez permitiría la introducción de un argumento externo (a veces materializado como FP adjunta por + SD).

\footnotetext{
${ }^{11} \mathrm{Si}$ bien, en la pragmática se podría aceptar una pasiva con el verbo desaparecer, dado el contexto sociopolítico de México, por ejemplo, en una noticia como "Los cuerpos fueron desaparecidos", técnicamente este verbo no tiene un sujeto agentivo, no obstante, puede ser coercionado. Esto es clave para entender el surgimiento del marco teórico de descomposición léxica que se verá en un apartado posterior.
} 
En español contamos con formas pasivas perifrásticas, a diferencia de otras lenguas donde son morfológicas. ${ }^{12}$ Tenemos construcciones — denominadas pasivas eventivas en esta investigación - que consisten en un auxiliar y participio, ambos en concordancia de número con sujeto oracional, el participio también de género, y con la marca de tiempo en el auxiliar (ejemplo 5) —-forma de pasiva típica del inglés también—, o bien con el clítico impersonal se + verbo, conocida como pasiva refleja, que concuerda en número con el objeto oracional y cuya marca de tiempo aparece en el verbo (ejemplo 6).

(5) Millones de cartas fueron escritas en esa época.

(6) Se escribian muchas cartas en esa época.

En el presente capítulo se analizarán los participios en las construcciones pasivas ${ }^{13}$ como la de (5) y se tratarán las propiedades semánticas del participio y de la construcción pasiva eventiva, pero no dentro del modelo de transformaciones de 57. Recordemos que a partir de la teoría de rección y ligamiento con el movimiento de elementos (move- $\alpha$ ) se considera que la derivación de construcciones pasivas y activas, entre otras, se realiza de manera independiente. ${ }^{14}$ Asimismo, se explicará el modelo de derivación del participio a

\footnotetext{
${ }^{12}$ Por ejemplo, en sueco kasta 'lanzar', kasta-s 'ser lanzado', en chichewa lemba 'escribir', lemb-edwa 'ser escrito' (Haspelmath y Sims, 2010: 237).

${ }^{13}$ Sin tomar en cuenta su índice de frecuencia en oposición con la pasiva refleja.

14 "Se consideraba que una huella era una categoría no realizada fonéticamente que heredaba las propiedades relevantes de interpretación del elemento movido, formando junto con este último un objeto discontinuo llamada cadena gramatical- Gran parte de la investigación dentro de la teoría de Rección y Ligamiento se dedicó a la caracterización de las propiedades del movimiento, de las huellas y de las cadenas, lo cual dio lugar, entre otras cosas a la tipología de las huellas (y categorías vacías, de manera más general)" (Corver y Nunes, 2007: 1). Las huellas de una FN resultaban del movimiento de un argumento, por ejemplo, el subíndice i muestra de dónde proviene la FN John en "John $n_{i}$ was kissed ti by Mary". En el marco teórico del
} 
partir de un elemento verbalizador de tipo $\mathrm{V}_{\mathrm{DO}}$ con base en la propuesta de Hale y Keyser (1993), Marantz (1997) y el análisis de Cuervo (2003); se introducirá la noción de Frase Participial; se describirá el papel de ser como auxiliar en esta construcción y se explorará el orden de constituyentes en la pasiva eventiva, i.e. aparente orden libre del sujeto (SV/VS). ${ }^{15}$

\section{Tipos de verbos en pasivas}

Un verbo inacusativo cuyo único argumento es un tema (undergoer) no aparece en construcciones pasivas, como se explicó en la sección anterior. Por ejemplo, caer, florecer, morir no forman pasivas eventivas: *Las hojas de los árboles son caídas, *Las plantas fueron florecidas, ${ }^{*}$ El hombre ha sido muerto. ${ }^{16}$ Son los transitivos el tipo de verbos que suelen aparecer en voz pasiva —El polvo es barrido todos los días, Las luces habían sido apagadas de repente-, ya que en su estructura semántica se permite tanto un argumento externo como un tema. Por su parte, aun cuando los verbos estativos e inergativos suponen no ocurrir en pasiva debido a que sólo cuentan con un argumento tema, pueden tener dos argumentos, o aparecer en progresivo, i.e. presentan alternancia respecto a transitividad y telicidad. Así, oler en La sopa huele bien, puede volverse transitivo en El chef huele la sopa y a su vez aparecer en progresivo El chef está oliendo la sopa frente a *La sopa está

minimalismo, "de acuerdo con la teoría de las copias, una huella es una copia del elemento movido que se borra en el componente fonológico (en el caso del movimiento explícito), pero que está disponible para ser interpretado en la Forma Lógica [...]." Por ejemplo, en una construcción pasiva como "[John] was kissed [John] by Mary", sólo la copia más alta está en la forma fonológica o spell-out, mientras que la copia más baja se borra: John was kissed [John] by Mary. (Corver y Nunes, 2007: 2).

${ }^{15}$ Nótese que (5) podría ser también: Fueron escritas millones de cartas en esa época.

${ }^{16}$ Aunque sí aparecen en construcciones con estar, como "El árbol está caído" o "Este hombre está muerto", las cuales serán tratadas más adelante. 
oliendo bien; medir es estativo en Miguel mide 1.80, que tampoco acepta la forma progresiva, y transitivo en El doctor está midiendo a la niña; enrojecer es ergativo en $L a$ mujer enrojeció de pena, transitivo en Enrojecimos a Juan con tanto piropo. Por lo tanto, bien podrían aparecer en formas pasivas: La sopa está siendo olida por los jueces de Masterchef, Los niños son medidos antes de pasar a consulta, El acero fue enrojecido al fuego y luego enfriado con lentitud. ${ }^{17}$

Tarald Taraldsen (2015) explica estas alternancias siguiendo el modelo de descomposición léxica propuesto por Ramchand (2007), el cual consiste en una sintaxis basada en la estructura del evento que contiene tres componentes (subeventos) importantes como cabezas funcionales: causa (Init), proceso (Proc) y estado resultante (Res).

(7) $\left[\text { InitP } \mathrm{DP}_{1} \text { Init }\left[\text { Proc } \mathrm{DP}_{2} \text { Proc }\left[\text { Res } \mathrm{DP}_{3} \text { Res }\right]\right]\right]^{18}$

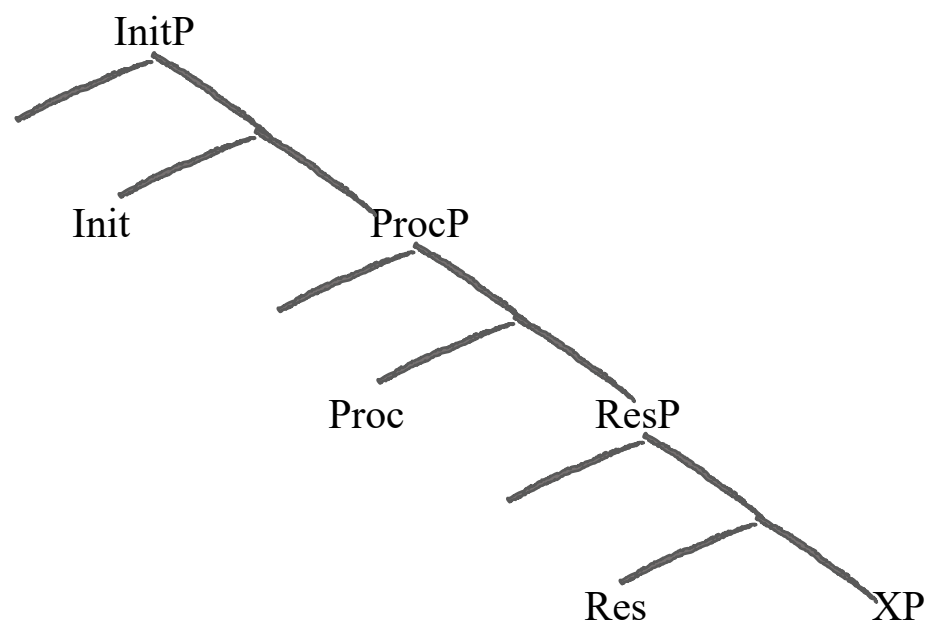

\footnotetext{
${ }^{17}$ Ejemplo adaptado de libro Teoría Mecánica de las construcciones para los estudios de la academia especial de ingenieros, pág. 26, obtenido en Google Books.

${ }_{18}$ Mantengo la forma del inglés DP (determiner phrase) en vez de SD (sintagma determinante) en la formalización de Ramchand y Taraldsen, para evitar confusiones.
} 
La interpretación es la siguiente: "La frase Res denota un estado que presenta el o los individuos denotados por $\mathrm{DP}_{3}$, mientras que ProcP denota un proceso en el cual el o los individuos denotados por $\mathrm{DP}_{2}$ ('el experimentante') participan. $\mathrm{DP}_{2}$ y $\mathrm{DP}_{3}$ pueden ser la misma DP, i.e. Spec-ProcP puede ser creado mediante fusión interna. Init introduce un 'iniciador' $\left(\mathrm{DP}_{1}\right)$, i.e. un individuo en un estado que dispara el proceso denotado por ProcP [...]. De este modo, Init es como un equivalente a la cabeza funcional llamada 'v pequeña"' (Taraldsen, 2015: 257). Considérese la oración (evento) "El dueño de la cervecería construyó la casa en $1645^{\prime 19}$ dentro del modelo presentado:

(8) [InitP El dueño de la cervecería Init [Proc la casa Proc [Res <la casa> Res]]]

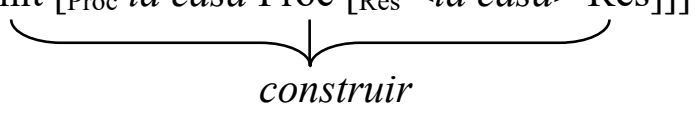

En el evento denotado en esta oración, El dueño de la cervecería es el DP1 (causa parte de InitP) que da lugar al proceso de construir Proc; la casa es el $\mathrm{DP}_{2}$ ("experimentante" del proceso de construcción), lo construido, por lo cual también es el $\mathrm{DP}_{3}$ Res (estado resultante=la casa construida). Ahora bien, Ramchand (2007: 90) explica que la alternancia de transitividad se debe a la ausencia de una de estas cabezas funcionales. Describe los inacusativos como una clase verbal que carece de la cabeza funcional Init en la descomposición eventiva. Recalca el hecho de que el único argumento del verbo comparte propiedades cruciales con los objetos de los transitivos y divide los intransitivos en dos tipos: (a) los de causación interna, como laugh, run, glow, sparkle; y (b) los de causación

\footnotetext{
${ }^{19}$ Ejemplo traducido de Taraldsen, 2015: 257.
} 
externa como break y open. Estos últimos tendrían la posibilidad de tener Init, es decir, presentar alternancia causativa/incoativa como en los siguientes ejemplos. ${ }^{20}$

(9a) Karena derritió la mantequilla.

(9b) La mantequilla se derritió.

(10a) Alex rompió la vara.

(10b) La vara se rompió.

En (9b) y (10b) sólo está la cabeza funcional Proc, mientras que en (9a) y (10a) sí se encuentra el nodo Init. En otros modelos, este último equivaldría al argumento externo, el cual puede ser nulo, como lo explicaré más adelante. Justamente, la cuestión de tener un verbo que se comporta de dos o más maneras distintas es clave para definir si se trata de un mismo verbo o dos verbos diferentes.

Pensemos ahora en la distinción estativo vs dinámico. La perspectiva adoptada en esta investigación es considerar la derivación a partir de raíces provenientes del lexicón, que tienen ciertos rasgos que van a ser valorados o no durante la derivación sintáctica. ${ }^{21}$

${ }^{20}$ En español tenemos el clítico se para los incoativos, en otras lenguas como en el inglés el verbo sería morfológicamente idéntico: Alex broke the stick / The stick broke.

${ }^{21}$ En una reformulación reciente de la hipótesis clásica de la GU se postula que el lenguaje es un sistema óptimo constituido por un mecanismo muy sencillo que ensambla palabras conforme a operaciones mínimas y a principios de interacción con los dos aspectos visibles de la expresión lingüística: el sistema de lo que articulamos -el sistema sensorio motor (SM)- y el sistema de los significados, los conceptos, los pensamientos -el sistema conceptual intencional $(\mathrm{CI})$ - . Se trata de una gramática interna diseñada con las mínimas especificaciones posibles. Ese sistema consta de un lexicón o diccionario mental, a saber: unidades que resultan de la combinación de rasgos interpretables y no interpretables escogidos de un repertorio universal, y de un sistema computacional o sintaxis estrecha (SC): un conjunto de reglas y principios combinatorios. Si las derivaciones están controladas por condiciones de legibilidad impuestas por el sistema computacional, la estructura de frase se puede reducir a esas necesidades mínimas: operará con rasgos en vez de con categorías, las únicas relaciones posibles serán la de hermandad estructural con dos facetas; la relación núcleo-complemento $(\mathrm{a}, \mathrm{b})$, y la relación de lo que está en el borde de la relación núcleo-complemento (c 
Así, tendríamos una sola raíz para el verbo medir que, en la estructura sintáctica, iría adquiriendo sus rasgos para contar con uno, en su forma estativa, o dos argumentos, en su forma dinámica. Compárese (a) y (b):

(a) estativo intransitivo

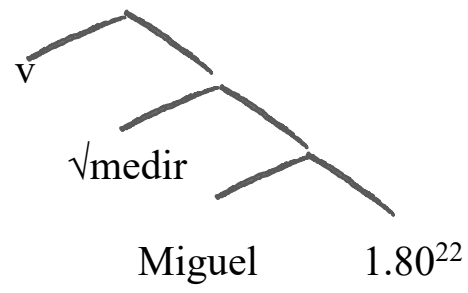

(b) dinámico transitivo

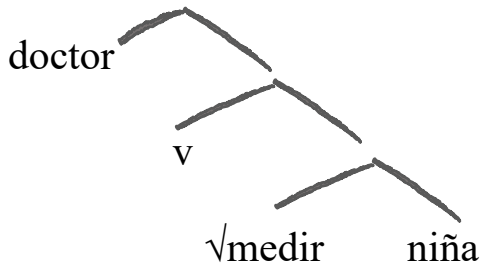

\section{Hipótesis de la v pequeña ${ }^{23}$}

Hale \& Keyser (en adelante H\&K) fueron los primeros en intentar deshacerse de la teoría de la estructura temática. Vincularon la cuestión del número de papeles temáticos con una cuestión morfológica: los verbos inergativos en muchas lenguas muestran señales de que su

respecto de $\{a, b\})$. El léxico interno es el depósito estructurado de los elementos de los que tiene que disponer el SC. Es posible que ese depósito no sea nada más que un conjunto de raíces, morfemas, unidades mínimas de significado léxico o gramatical quizá en algunos casos hasta desprovistas de rasgos categoriales pues éstos aparecerían en la computación (Chomsky, 2002, 2004, y el Programa Minimalista, citado en Violeta Demonte, 2003; Borer, 2015).

${ }^{22}$ Es posible considerar que el significado intrínseco de medir, en su función intransitiva, exige la expresión de la medida de una magnitud. Podríamos o no estar de acuerdo en *Miguel mide/*Miguel pesa frente a Miguel mide 1.80/Miguel pesa 80 kilos. Hay debate respecto a la categoría sintáctica a la que pertenecen dichos complementos. Sobre este tema, véase P. Pablo Devís Márquez (2008), "Complementos verbales de medida no preposicionales en español”, en Revista Española de Lingüística, núm. 38, pp. 95-126. Como esta discusión se encuentra fuera del alcance de la presente investigación, me limitaré a postularlo como un

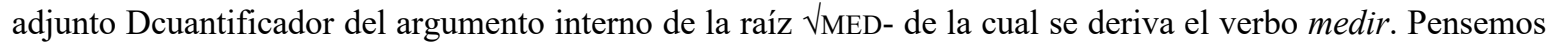
que también se puede decir Miguel mide los 1.80 necesarios para la prueba física/Miguel pesa unos 90 kilos.

${ }^{23}$ Tomado de Harley, 2011: 427-448. 
derivación involucra un nominal que denota un evento y un verbo "ligero" agentivo (generalmente glosado como “do").

Lengua jemez (Nuevo México)

(11) záae-'a

canción-do

"cantar"

(12) hịl-'a

risa-do

"reír"

(13) se-'a

discurso-do

"hablar"

Lengua vasca

(14)

(15) "dormir"

risa do

"reír"

(16) zurrunga egin

ronquido do

"roncar"

En inglés esta relación parece ser evidente tomando en cuenta que los nominales eventivos tienen su verbo inergativo correspondiente:

$$
\begin{gathered}
\text { a laugh - to laugh } \\
\text { a run - to run } \\
\text { a walk - to walk } \\
\text { a swim - to swim } \\
\text { a sneeze - to sneeze }
\end{gathered}
$$

$\mathrm{H} \& \mathrm{~K}$, con base en estas observaciones, propusieron que hay estructuras transitivas subyacentes en las cuales un verbo ligero agentivo selecciona e incorpora, opcionalmente, 
su objeto nominal escueto. Este morfema verbal nulo en los inergativos del inglés explicaría la correlación entre verbos inergativos y nominales escuetos. Así, una sola estructura daría cuenta del inglés, el vasco y el jemez.

Ejemplos de derivación verbal inergativa en tres lenguas
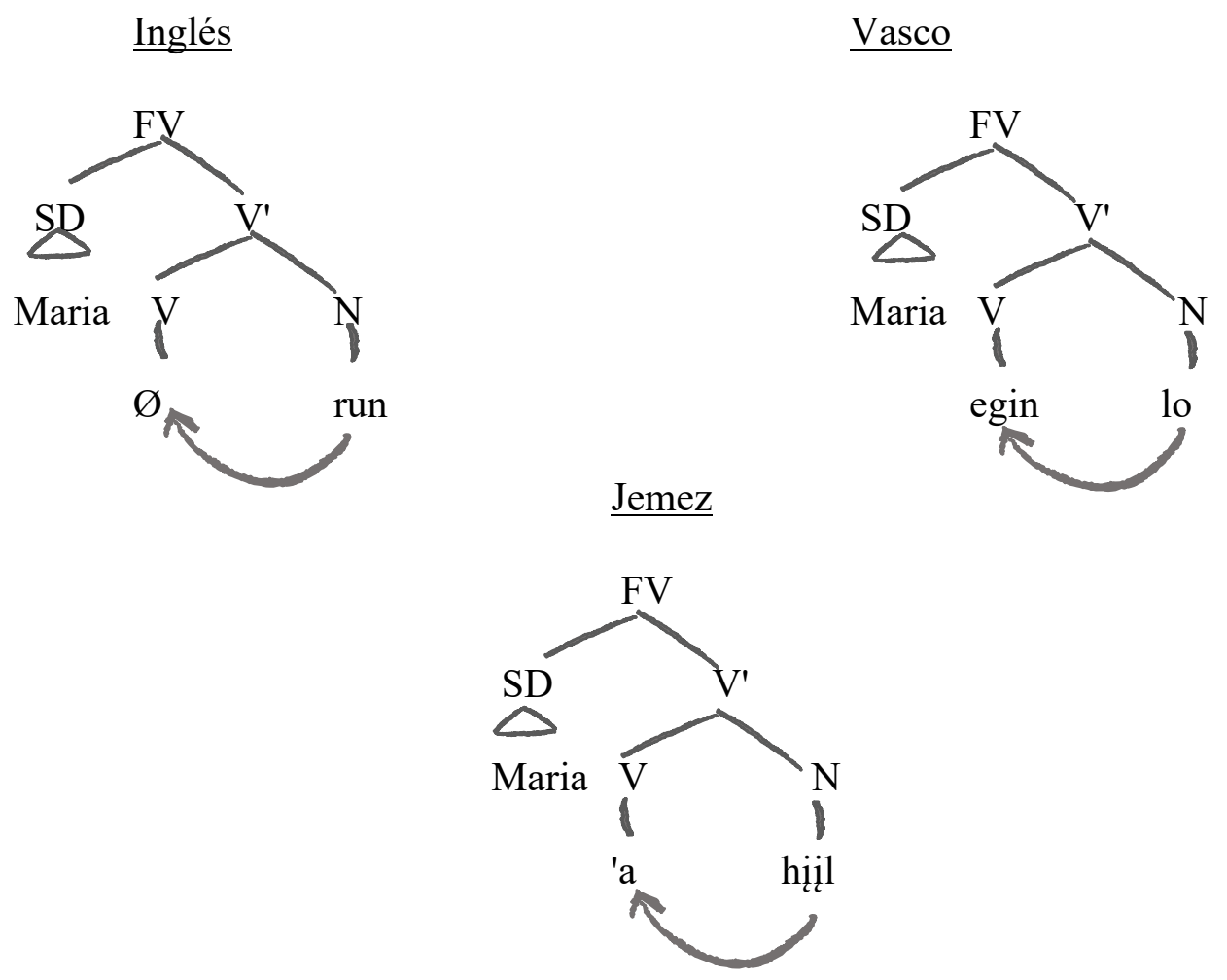

Así, esa $\mathrm{V}-\varnothing$ en inglés, egin en vasco, 'a en jemez- devino en la noción de v pequeña. $\mathrm{H} \& \mathrm{~K}$ consideraron estos datos comparativos para indicar la presencia de una estructura subyacente uniforme, según la cual hay una proyección verbal especial ('do') que introduce y asigna el rol temático de Agente. La propuesta también explicaría que sólo hay un rol porque sólo hay un asignador funcionando. H\&K extendieron su análisis a otros verbos que asignaban papel de Agente para dar cuenta de la alternancia causativa/incoativa. En varias lenguas, el significado de muchos incoativos implica 'volverse (más) ADJ'. Por ejemplo: 
(18)

$\begin{array}{lll}\text { Español } & \text { enrojecer } & \text { rojo } \\ \text { Inglés } & \text { redden } & \text { red } \\ \text { Yaqui } & \text { sikisi } & \text { siki }\end{array}$

Formularon, asimismo, que los verbos incoativos son versiones incorporadas de construcciones resultativas inacusativas, en otras palabras, "el cielo enrojeció" implica que adquirió un estado de rojez. Así, The sky reddened más o menos equivale a The sky turned red (El cielo se volvió rojo). ${ }^{24}$

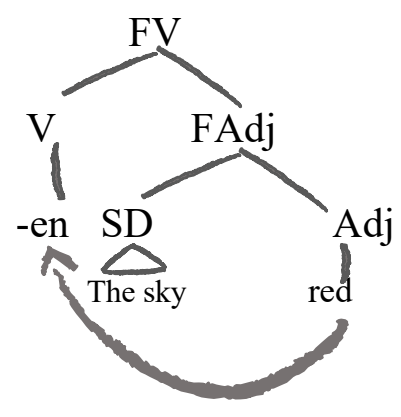

Estos verbos, a diferencia de los inergativos, pueden ocurrir en una estructura transitiva con un argumento Agente, como "The sun reddened the sky", por ejemplo. Este tipo de verbalizador es, entonces, la cabeza que introduce un argumento externo agentivo como su especificador. Ramchand (2007) se refiere a este elemento como Init (inititator u objeto de causa).

\footnotetext{
${ }^{24}$ Los ejemplos en (19) y (20) no muestran el nodo tiempo. Por fines prácticos, se mantiene una estructura simple, sobreentendiéndose una oración en perfecto.
} 
(20) The sun redenned the sky (El sol enrojeció el cielo).

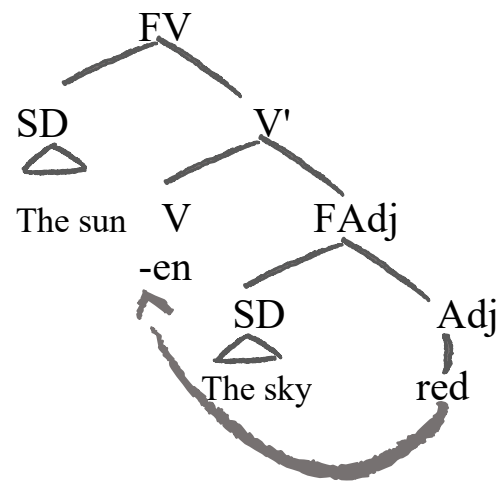

Asimismo, sugirieron una ubicación invariable para el argumento tema. El objeto directo recibió la cualidad canónica de tema, por lo cual fue también denominado sujeto interno, mientras que ser agente significa estar en posición de especificador de la frase verbal (FV). H\&K extendieron su análisis a un tercer tipo de verbos en los cuales una frase preposicional (FP) es el complemento del argumento externo que selecciona V: [X cause $\mathrm{Y}$ on/at/with Z], como en:

(21) The cowboy saddled the horse (El vaquero ensilló al caballo). ${ }^{25}$

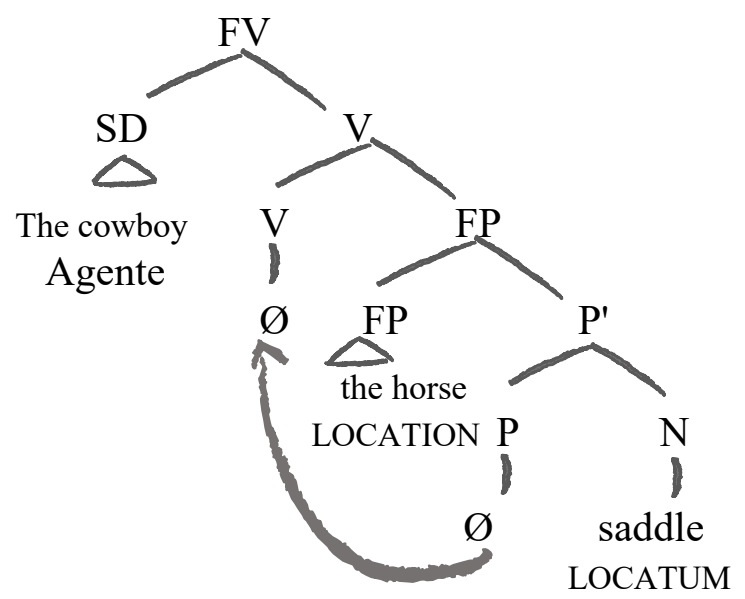

\footnotetext{
25 Otros verbos: vendar, ensillar, empanizar, vestir, engrasar, enganchar, pintar, pimentar, empolvar, salar, condimentar, regar, entintar, etc. (Harley, 2008: 12; traducidos del inglés).
} 
Aunque hay verbos que no incorporan adjetivos ni nominales en su denotación, la posición de v es llenada con un predicado verbal genuino. Por ejemplo, (22) los verbos de creación/consumo serían como los inergativos; (23) los de transferencia, como los de location/locatum y (24) los de cambio de estado como los inacusativos/incoativos, o como los causativos con $\mathrm{V}$ agentiva.

(22)

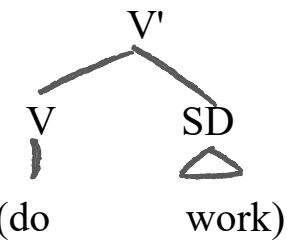

$\begin{array}{ll}\text { comer } & \text { una manzana } \\ \text { escribir } & \text { un poema } \\ \text { hacer } & \text { un baile } \\ \text { hacer } & \text { un handout }\end{array}$

(24)

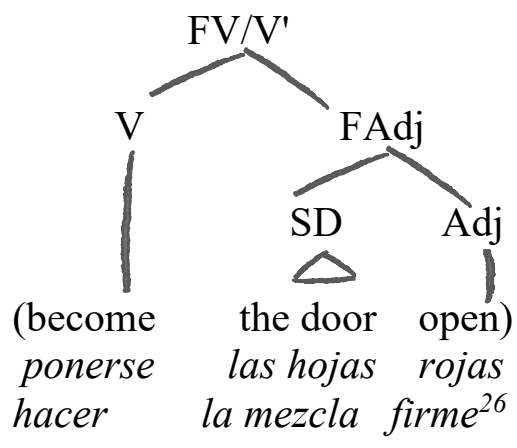

(23)

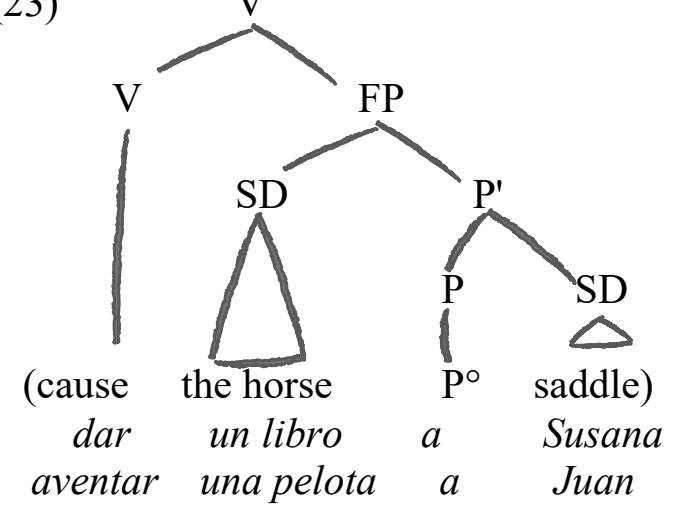

${ }^{26}$ En inglés, become the batter stiff. 
De esta manera, estas tres categorías verbales se convirtieron en tres tipos de $\mathrm{v}$ pequeña. ${ }^{27}$ En otras palabras, se trata de ver la composición de significados verbales por medio de la conjunción de dos (o más) predicados por separado.

Entonces, las llamadas $v$ pequeña son elementos verbalizadores dentro de las frases verbales que dan lugar a distintos tipos de verbos. A partir de lo propuesto por H\&K, han surgido diversos análisis para la derivación de verbos, que puede involucrar básicamente tres núcleos verbales funcionales diferentes: $v-1 / \mathrm{v}_{\mathrm{DO}} \mathrm{y} \mathrm{v}-2 / \mathrm{v}_{\mathrm{GO}}$, para dar cuenta de verbos transitivos e inergativos que presentan un argumento sujeto y para verbos inacusativos, respectivamente (Marantz, 1997; Cuervo, 2003) y para verbos no dinámicos, $\mathrm{V}_{\mathrm{BE}}$ (Cuervo, 2003).

(25) El cartero está trayendo tu carta. (traer $\left.=\mathrm{v}-1 / \mathrm{v}_{\mathrm{DO}}\right)$

(26) El globo está cayendo. $\left(\right.$ caer $\left.=\mathrm{v}-2 / \mathrm{v}_{\mathrm{GO}}\right)$

$(27) *$ El cartero está sabiendo la dirección. $\left(\right.$ saber $\left.=v_{\mathrm{BE}}\right)$

Parte de la propuesta de esta investigación es considerar los siguientes tipos de $\mathrm{v}$ pequeña para explicar la derivación de participios en las construcciones pasivas, resultativas y estativas en cuestión. Consideraré $\mathrm{V}_{\mathrm{DO}}$ para los verbos transitivos e inergativos, $\mathrm{v}_{\mathrm{GO}}$ para los inacusativos, $\mathrm{v}_{\mathrm{BE}}$ para los estativos. Cuervo (2003: 23-26) considera cinco tipos de eventos en su análisis de dativos en español, que a su vez divide en tres eventos simples, que son actividades, cambios, estados, y dos complejos, causativos e

\footnotetext{
${ }^{27}$ Para los verbos meteorológicos, como rain y snow, H\&K propusieron que incorporan un nominal en la V no agentiva $B E C O M E$ y se debe insertar un expletivo para satisfacer el principio de proyección extendida (EPP), el cual, recordemos, hace que una unidad sintáctica pueda ser fusionada en posición de especificador de una categoría en la que sus rasgos contengan esta propiedad.
} 
incoativos. En esta investigación se considerarán los tres primeros: siguiendo a Cuervo, los predicados de actividad serán resultado de la fusión (merge) entre la raíz y $\mathrm{v}_{\mathrm{DO}}$; los de cambio, entre la raíz y $\mathrm{v}_{\mathrm{GO}}$; los estativos, entre la raíz y $\mathrm{v}_{\mathrm{BE}}$.

\section{TABLA 1: TRES TIPOS DE V PEQUEÑA}

\begin{tabular}{|l|l|l|}
\hline Derivados de $\mathrm{v}_{\mathrm{DO}}$ & Derivados de $\mathrm{v}_{\mathrm{GO}}$ & Derivados de $\mathrm{V}_{\mathrm{BE}}$ \\
\hline Bailar (tango) & Caer & Saber \\
Barrer & Crecer & Oler (bien/mal) \\
Apagar & Morir & Faltar \\
Oler (una flor) & Florecer & Medir \\
Medir (la mesa) & Romperse & \\
Romper (el vaso) & Enrojecer & \\
Enrojecer (el metal) & Único argumento es Tema & Único argumento es Tema \\
\hline $\begin{array}{l}\text { Permiten argumento Tema } \\
\text { (interno) y Sujeto o Agente } \\
\text { (externo) }\end{array}$ & (undergoer) & \\
\hline
\end{tabular}

Fuente: Elaboración propia.

Nótese que hay verbos que se repiten en las columnas. La propuesta de derivación por medio del elemento $\mathrm{v}$ pequeña da cuenta de la diferencia de significado: depende a partir de qué tipo de v se derive el verbo, va a denotar distintas cosas. Como se mencionó anteriormente, los verbos inacusativos (en esta propuesta, los derivados de $\mathrm{v}_{\mathrm{GO}}$ ) no aparecerán en construcciones pasivas. La cuestión radica en que los participios de dichas construcciones, si bien aceptan verbos dinámicos (ambos derivados de $\mathrm{v}_{\mathrm{DO}} \mathrm{y} \mathrm{v}_{\mathrm{GO}}$ lo son), sólo los de $\mathrm{V}_{\mathrm{D}}$ podrán adquirir el significado pasivo. Hay inergativos que pueden ser pasivos como correr y jugar "10 kilómetros fueron corridos este domingo en el maratón" y "Fueron jugados 10 partidos ayer" o "este partido fue jugado como nunca", habrá otros que no, como sonreír. Así, algunos presentarán alternancia de transitividad, otros no. 
Ramchand (2007: 97) menciona que se ha propuesto que la pasiva es como un sabor particular de $\mathrm{v}$ pequeña, pero que considerar una cabeza funcional PASS no esclarecería por qué no hay construcciones de pasiva con verbos inacusativos. Explica que si bien la formación de una pasiva se obtiene mediante diferentes mecanismos, uno de ellos consiste en la "omisión" del argumento en Init, i.e. el agente o causa, y no se aplica cuando éste no es proyectado e identificado subyacentemente. En los verbos inacusativos al no estar presente este componente, no es posible formar pasivas. Ahora bien, aunque en las pasivas el agente está "ausente", de cierto modo se encuentra presente semánticamente. Es por ello que se permiten cláusulas adverbiales de propósito y causa en estas construcciones, y no con verbos inacusativos:

(28) La pelota fue aventada para molestar a Alex/deliberadamente/por Kayleigh.

(29) El niño creció *para enorgullecer a su papá/*deliberadamente/*por María.

Equiparando la derivación propuesta para el incoativo enrojecer como transitivo (ejemplo 20) con uno de la tabla, como apagar, cambiando las frases verbales por $\mathrm{v}$ pequeña, tendríamos:

(30) Derivación de enrojecer y apagar como transitivos.
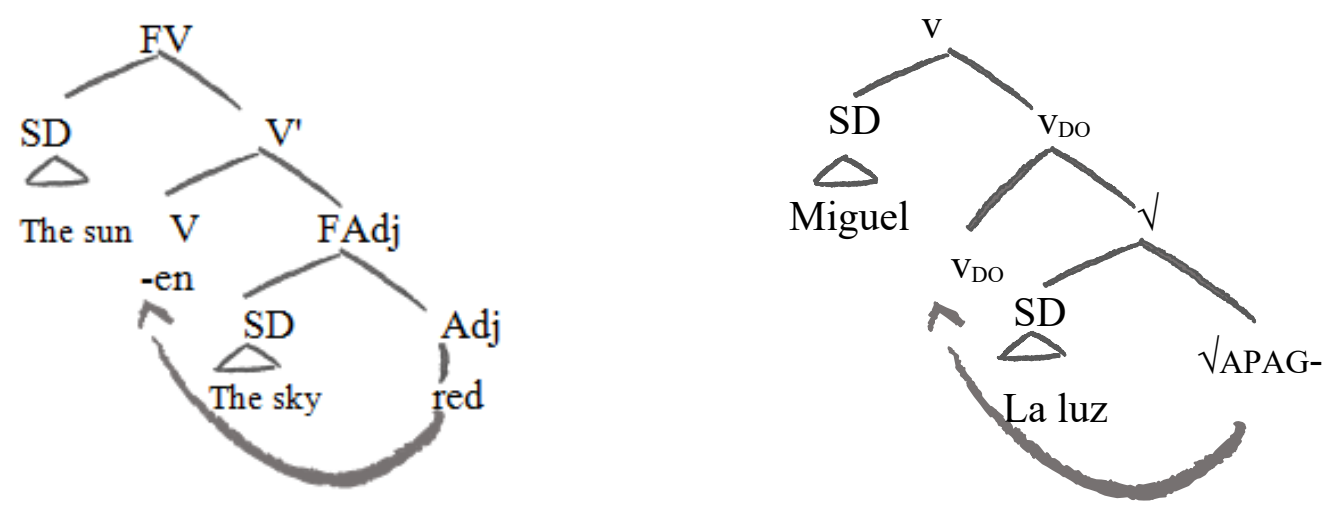
Mientras que apagar como incoativo no se derivaría a partir de $\mathrm{v}_{\mathrm{DO}}$, sino de $\mathrm{v}_{\mathrm{GO}}$, dado que denota un cambio que le sucede al argumento interno.

(31) La luz se apagó.

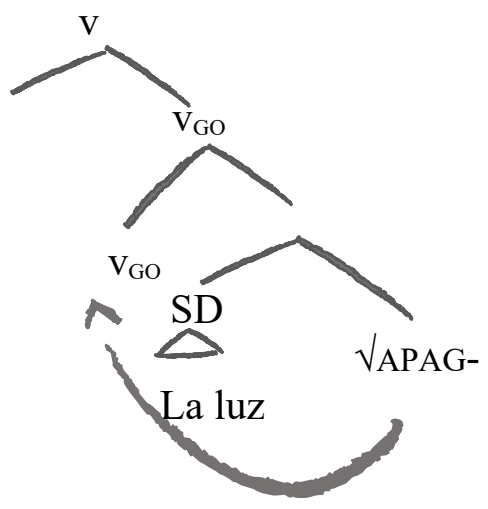

\section{Estructura y características de la pasiva: sobre ser y el participio}

Podemos pensar en la noción de luces apagadas, opciones reducidas, jefe informado, cara alargada, gato divertido (con/por algo), gente alocada como si los participios denotaran características de los nominales que acompañan. Estas mismas frases pueden ser extendidas a oraciones en voz pasiva como en:

(32) Las luces fueron apagadas a las 5 ayer.

(33) Las opciones han sido reducidas a tres.

(34) El jefe es informado de los pormenores segundo a segundo.

(35) Su cara está siendo alargada en la cirugía.

(36) El gato es distraído con una bola de estambre para que no moleste a los invitados. 
(37) La gente ha sido alocada por tanto rumor. ${ }^{28}$

En la literatura se ha analizado la similitud entre oraciones pasivas y atributivas dado que comparten la misma estructura y comparten ciertas características como la posibilidad de pronominalización y la conmutación de ser por otros verbos similares. (Brucart, 1990). Véanse los siguientes ejemplos:

(a) Fue bello. = Lo fue. (atributiva)

(b) Fue multado. = Lo fue. (pasiva)

(c) La casa es/está/parece/resulta vieja. (atributiva)

(d) La casa es/está/parece/resulta destruida. (pasiva)

No obstante, Brucart y otros observan que el participio de las pasivas no sólo tiene rasgos diferentes de los nominales o adjetivos que aparecen en oraciones atributivas, sino también de los participios en construcciones de perfecto. Como en este capítulo nos concierne la caracterización de las pasivas, sólo mencionaré aquí lo que distingue participios de pasivas de los de perfecto. En la tradición el participio ha sido considerado como un adjetivo verbal, dado lo antes mencionado. No obstante en las construcciones pasivas (y en las resultativas del siguiente capítulo), es evidente que el carácter del participio es definitivamente verbal, aunque en la construcción de perfecto haber + participio, formará una unidad sintáctica, y en la pasiva ser + participio no. En la primera no hay concordancia: La actriz ha asistido a la fiesta; mientras que en la pasiva sí: La actriz fue elogiada por la crítica. En segundo lugar, existe la posibilidad de interpolar

\footnotetext{
${ }^{28}$ Aclaro que mi corpus de ejemplos no tiene que ver con la frecuencia de uso de una forma pasiva u otra en español, esto es, si la estructura conocida como pasiva refleja sería más o menos "adecuada" que la estructura de pasiva analizada en esta investigación. Considero como formas posibles estas construcciones con ser + participio con el sentido de pasiva.
} 
modificadores entre ambos elementos de la pasiva, como en La edición fue completamente retirada del mercado frente a *El editor había completamente retirado la edición del mercado. En el tiempo perfecto, considerando sus elementos como una unidad sintáctica, haber es el auxiliar aspectual que dará el sentido de perfectividad, no el participio, como se ha considerado en la tradición, dado que éste aparece también en construcciones pasivas y atributivas que no contienen dicha interpretación aspectual.

Respecto a ser, ya varios autores han considerado que es simplemente un soporte de los rasgos de flexión oracional, sin capacidad predicativa, es decir, funciona como una mera conjunción, de ahí que sea también denominado un elemento copulativo (Brucart, 1990: 200). Y recalco elemento copulativo y no verbo, porque incluso Gómez Hermosillo, desde 1835, decía que si bien en su origen, ser era un verbo, ya no lo es, y que "su oficio es el de indicar cierta relación abstracta entre dos ideas: oficio propio de las conjunciones..." (Gómez Hermosillo, 1835: 44). Sin ahondar más en el asunto, por el momento lo identificaremos como soporte para Tiempo en la construcción pasiva. En la sección que sigue a este capítulo proporcionaré más argumentos para considerarlo como tal.

\section{Derivación de una pasiva: Frase participial}

Introduzco la noción de frase participial (FPart) para dar cuenta de la derivación del participio, ya sea para la construcción pasiva, resultativa o estativa. En las dos primeras la raíz adquirirá rasgos verbales mientras que en la última, no habrá un elemento verbalizador, ya que la estructura carecerá de ese carácter dinámico. 
En una oración pasiva como Las luces fueron apagadas (por el conserje), en la primera fase de derivación tenemos la raíz léxica con su argumento interno en una primera instancia de fusión o merge.

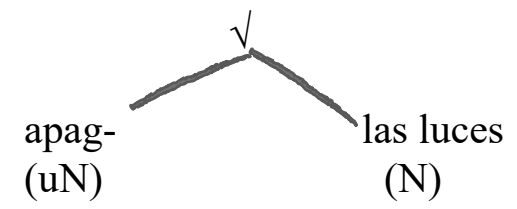

Pensemos que la raíz apag- tiene un rasgo no valorado de nominal (uN) y como las luces tiene un rasgo valorado de nominal $(\mathrm{N})$, por eso se permite la fusión o ensamble. En otras palabras, cuando pensamos en qué significa apagar, apagón, apagamiento, apagado (piénsese que en este momento no sabemos qué categoría será nuestra raíz), siempre involucra que algo se apaga, por ponerlo en términos muy simples. Ese algo será el argumento interno. La concordancia de género y número se da en el primer momento de fusión de la raíz con su DP.

En un segundo paso de la derivación, esta raíz adquirirá su categoría; i.e. ¿será un verbo, un nominal, un adjetivo? Aquí es donde interviene el elemento verbalizador como cabeza funcional en la estructura: la $\mathrm{v}$ pequeña de tipo $\mathrm{V}_{\mathrm{DO}}$. Como se explico en párrafos anteriores, este elemento le agregará un cierto "sabor" a nuestra raíz: un rasgo dinámico que dará paso a la denotación de un proceso, además de permitir que, aparte del argumento interno, haya uno externo que será la causa o agente, ya sea expresado o no en spell-out.

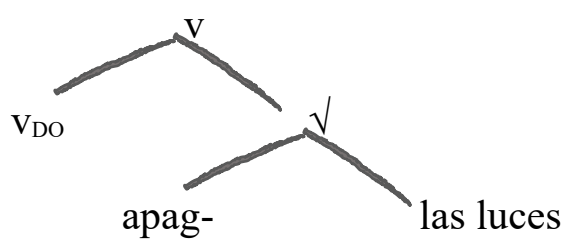


En este punto, la raíz se va a borrar y copiar para adquirir su rasgo verbal en la proyección de $\mathrm{V}_{\mathrm{DO}}$.

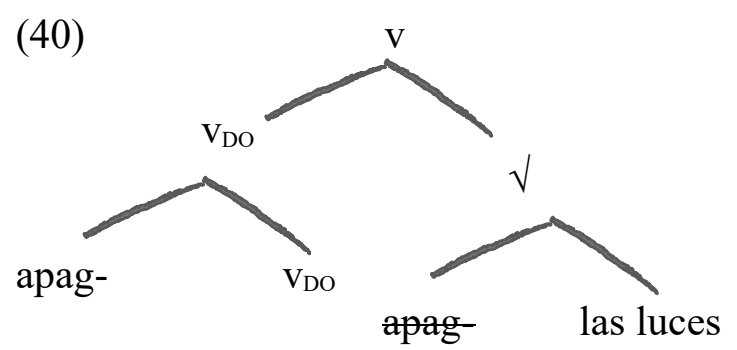

Dada su derivación como verbo a partir del elemento vDO, el especificador de v será una posible causa o agente, ya sea que aparezca o no en spell-out.

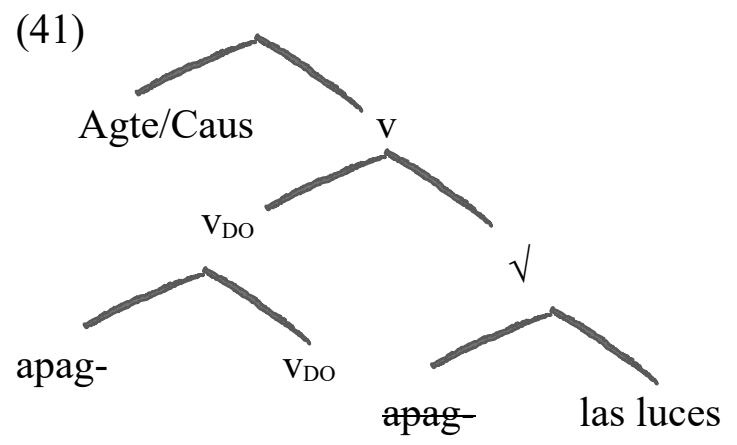

Una vez adquirido su rasgo verbal de tipo $\mathrm{v}_{\mathrm{DO}}$, se vuelve a borrar y copiar para ensamblarse con el morfema de participio en la proyección de la Frase Participial, llevando consigo los rasgos de concordancia de su argumento interno. En el rectángulo proporciono el spell-out. 


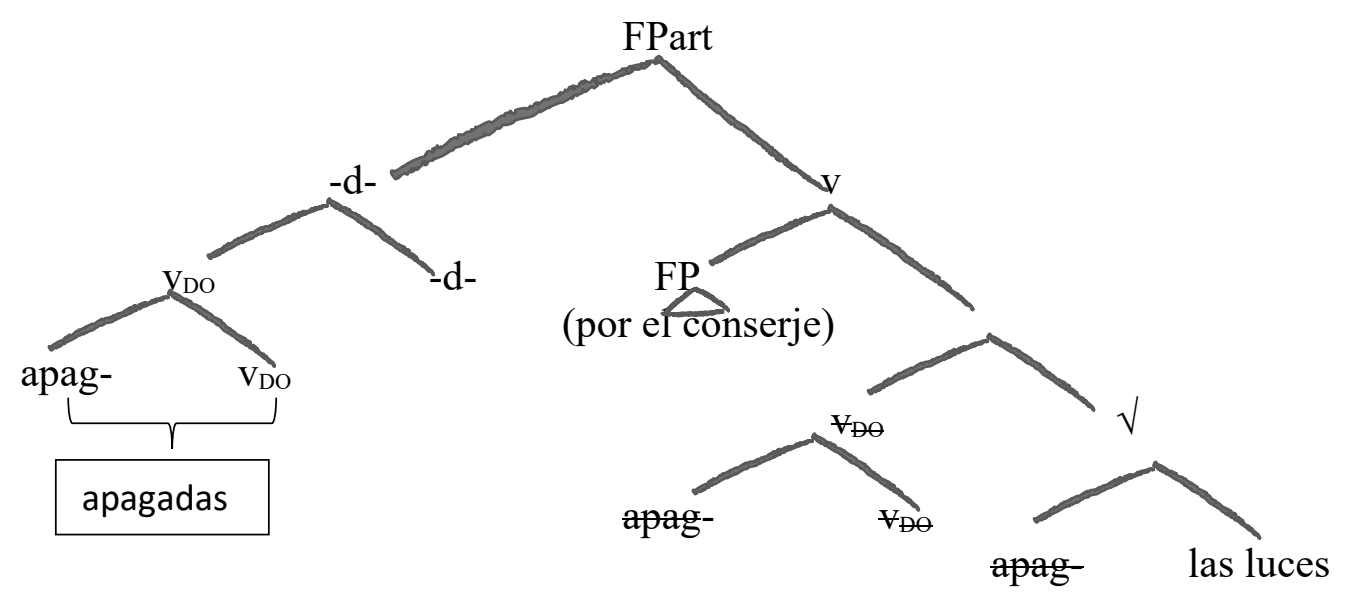

$\mathrm{Al}$ adquirir el morfema de participio, el verbo exige que el agente o causa, en caso de materializarse, sea una frase preposicional (FP). Puede que el hablante sepa o no quién efectuó la acción o qué fue lo que provocó lo sucedido, pero sabe que alguien o algo lo hizo dada la naturaleza de la estructura, por tanto, en el ensamblaje de piezas de nuestro sistema computacional el espacio asignado para ese agente o causa está presente y el "sabor" de esa v pequeña lo garantiza.

¿Qué pasa después de haberse formado el participio? Hasta aquí, tendríamos que (i) $\mathrm{X}$ apagado a causa de $\mathrm{Y}$. La formación de la pasiva eventiva requiere un elemento que nos permita expresar cuándo sucedió esto. Ese elemento será la cópula ser. Como se dijo anteriormente, nos servirá para anclar el tiempo de referencia del evento (i), así que simplemente se va a insertar por encima de FPart, lo cual se representará como S. Recordemos que en esta etapa todavía no se materializa nada en spell-out, estos elementos en realidad siguen es la abstracción de nuestro sistema computacional. 


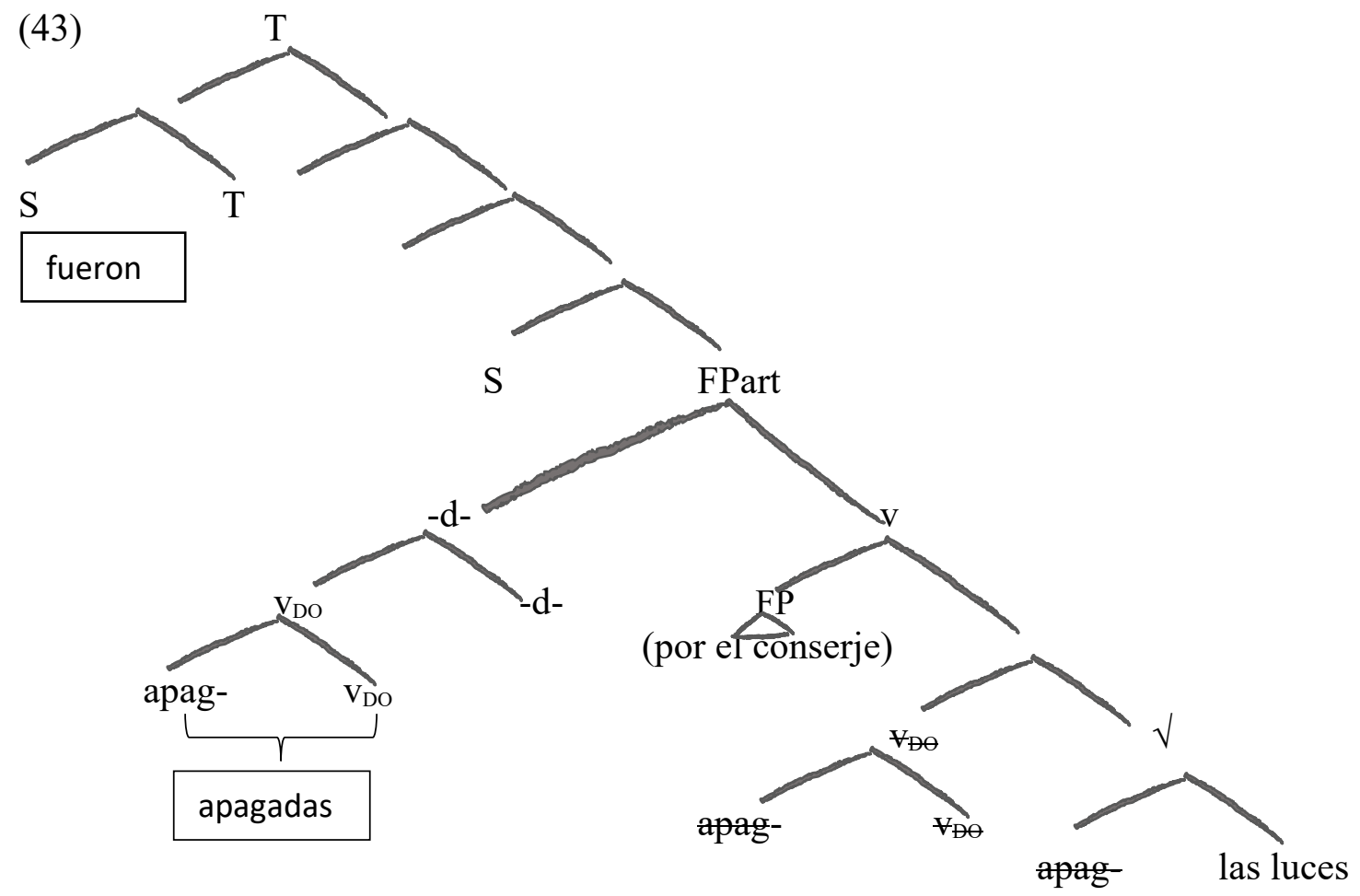

En el rectángulo nuevamente se muestra cómo sería la materialización de este último elemento añadido. Si quedara así, resultaría en la oración Fueron apagadas las luces, la cual puede considerarse como una oración aceptable en el español mexicano. Es sabido que el orden de constituyentes responde a cuestiones principalmente pragmáticas siendo esta lengua considerada de orden libre. Cuando se da otro orden, se lleva a cabo de nuevo la operación copiar-borrar. Pero antes de ver estas posibilidades, veamos qué otros elementos podrían entrar en juego en los espacios entre T y FPart.

Una oración como "Las luces han estado siendo apagadas desde las 6" en un contexto donde hay muchas luces que apagar y por tanto el proceso toma $\mathrm{X}$ tiempo. La cuestión aquí es el tiempo perfecto y el aspecto progresivo, los cuales solicitan la presencia de haber y estar como auxiliares. En este caso, dado que haber será nuestro soporte para el tiempo, ser fungirá como soporte para el afijo -ndo que exige el progresivo. Todo lo anterior puede ser representado de manera simple como: 


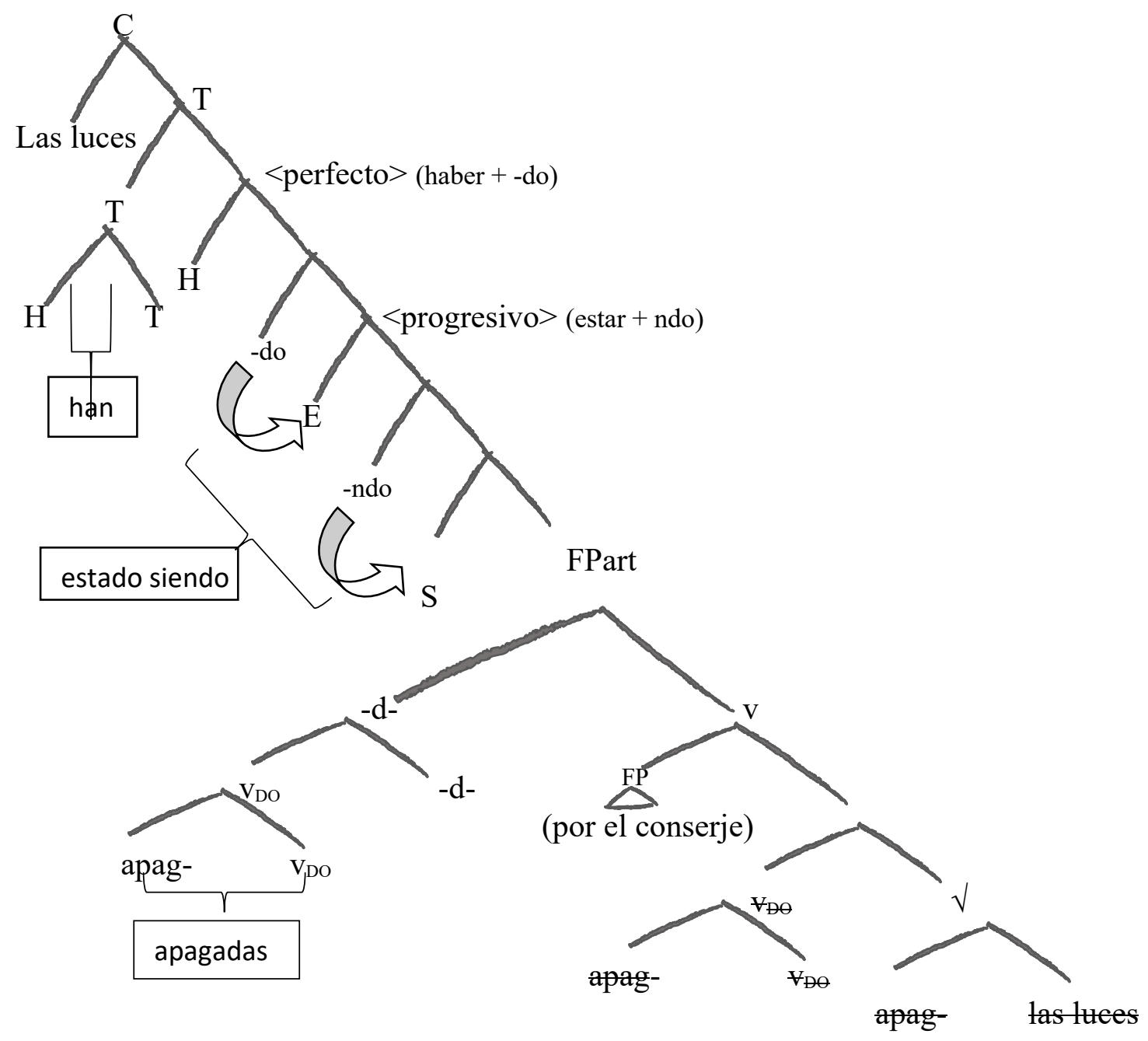

Recordemos a Chomsky (1957) y la regla de Affix Hopping, de acuerdo con la cual el afijo que pertenece a un auxiliar se mueve al siguiente verbo o auxiliar. Por ejemplo, un modal necesita un infinitivo a su derecha, el perfecto y participio, el progresivo un gerundio y el pasivo un participio. Esta regla es un conjunto de instrucciones que dicta que si en una 
secuencia nos encontramos con un afijo seguido por un elemento auxiliar o verbal, este afijo se adhiere al siguiente elemento inmediato. En el caso de (44), el aspecto perfecto involucra un auxiliar haber, y el requisito de que el elemento verbal que le sigue tome la forma de un participio (simbolizado como - do) y el aspecto progresivo requiere que el verbo que le sigue aparezca en la forma de gerundio (simbolizado como $-n d o$ ). Si ambos

aspectos aparecen, el morfema de participio - do debe realizarse en el auxiliar estar y el morfema -ndo en el siguiente elemento. Como se trata de una pasiva, el siguiente elemento debe ser participio, así que ser se insertará como soporte del morfema de progresivo; esta vez haber será el que portará el morfema de tiempo dada la secuencia gramatical.

\section{Orden de constituyentes}

En (43) Fueron apagadas las luces tenemos el orden ser + participio + Sujeto Tema. Dicho evento puede ser expresado también como Las luces fueron apagadas o incluso Fueron las luces apagadas, esta última ya sea como una afirmación o pregunta. ¿Cómo es posible esta alternancia-? Dado que el sujeto de la pasiva es el argumento interno del participio, sabemos que se ha fusionado con este elemento y así se encuentra junto a la raíz; por tanto, puede quedar in situ. Del mismo modo, se permite este orden en una construcción interrogativa representada en (45). Nótese que si la respuesta a una pregunta Qu- o de información nueva es una oración completa, o con al menos un elemento más aparte de la información precisa, caben diferentes posibilidades en el orden de constituyentes, dependiendo del contexto de enunciación, como en (46), es decir, tiene que ver con cuestiones de índole pragmática, más que sintáctica. 
(45)¿A qué hora fueron apagadas las luces ayer?

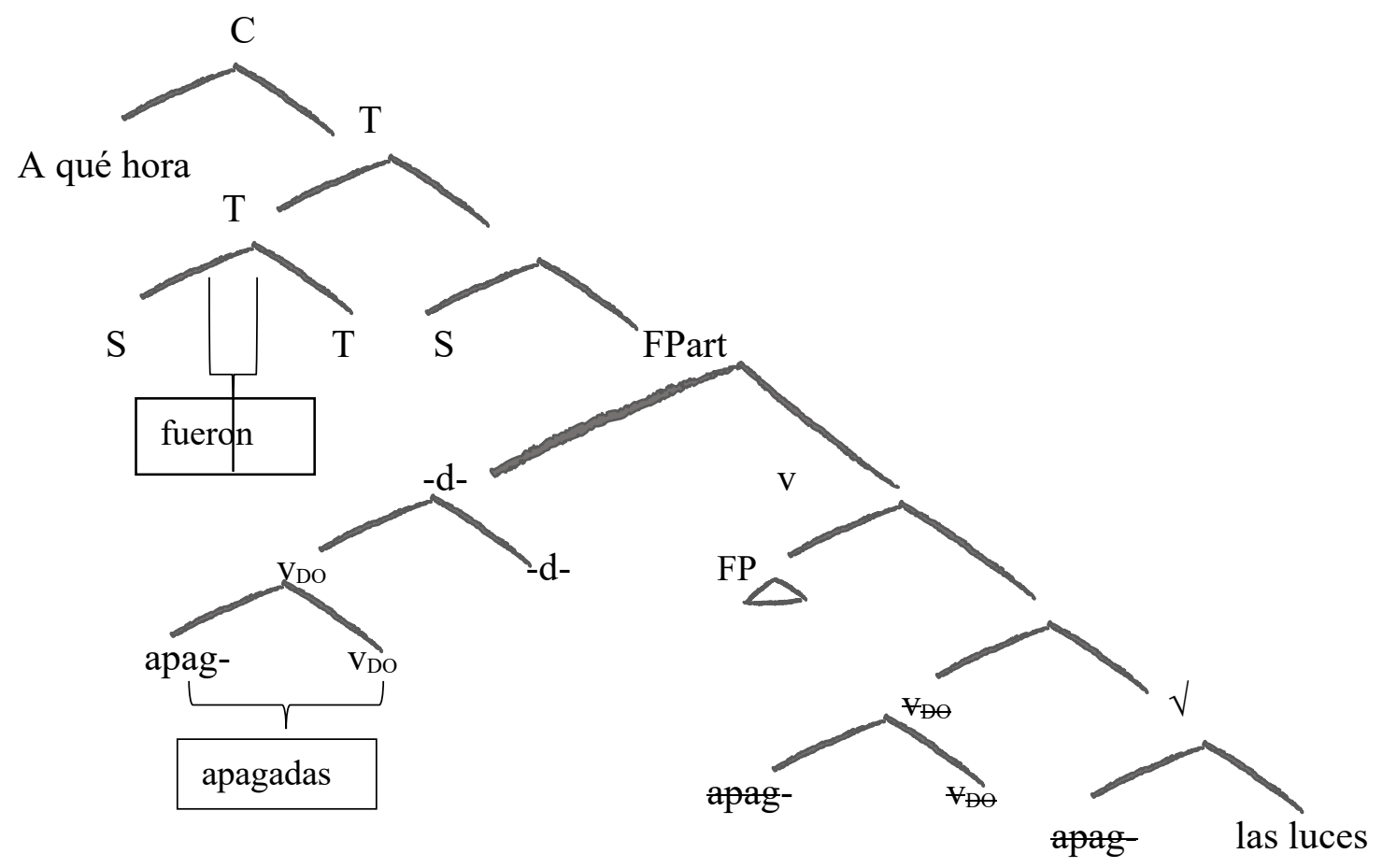

(46)

a. Las luces fueron apagadas a las 5 .

b. A las 5 fueron apagadas (las luces).

c. Fueron apagadas a las 5 las luces.

d. Las luces, a las 5 fueron apagadas. 


\section{Interludio: ser \& estar}

Las cópulas del español presentan asimetrías respecto a los elementos que seleccionan como elementos atributivos de sus sujetos en una oración y en cuanto a su comportamiento como auxiliares. Han sido estudiadas desde diversas perspectivas, principalmente en términos de diferencias de tipo aspectual, como ejemplifican las oraciones "Ramón es triste" (estado permanente) vs. "Ramón está triste" (estado transitorio) (Munguía, 2016: 268). Igualmente, esta diferencia se ha explicado en términos de perfectividad de los adjetivos (que seleccionan estar) e imperfectividad (que seleccionan ser) (Hanssen, 1913, citado en Lema, 1994: 37 y en Gallego y Uriagereka, 2009: 2), características descritas en términos carlsonianos de propiedades de Nivel de Estadio $($ Stage-Level $=\mathrm{SL})$ para construcciones con estar vs. Nivel de Indviduo (Individual Level = IL) para las de ser. Las diferencias entre estos elementos es uno de los temas más trabajados en sintaxis del español. En la presente investigación, me propongo solamente describir algunos estudios relevantes al respecto, con el fin de argumentar la postura adoptada para diferenciar las estructuras pasivas y estativas con participios en español. Esclarecer totalmente las diferencias y similitudes entre estos dos elementos queda fuera del alcance del presente análisis.

Básicamente, hay dos vertientes: enfoques aspectuales, que explican las diferencias entre ser y estar en términos de aspecto/estructura del evento/Aktionsart, ${ }^{29}$ y enfoques comparativos $^{30}$ que analizan cómo se atribuyen las propiedades a los sujetos. Ambos

\footnotetext{
${ }^{29}$ Ver referencias citadas para “aspectual approaches"en Gumiel, Moreno y Pérez (2015: 120, de aquí en adelante GMP, 2015).

${ }^{30}$ Ver referencias citadas para “comparison-based approaches" en GMP (2015: 120).
} 
enfoques buscan dar cuenta del hecho de que algunos adjetivos combinan sólo con una de las cópulas y otros con ambos en oraciones copulativas con predicados adjetivales. En ambos enfoques se encuentra implementada la distinción de Nivel de Individuo (Individual Level / IL) y Nivel de Estadio (Stage Level / SL) para explicar la distribución de las cópulas. En pocas palabras, esta distinción -introducida por Carlson (1977) en su Reference to Kinds in English - se basa en las propiedades que son parte del individuo, permanentes, resultado de una comparación entre individuos (IL) frente a propiedades de estadios del individuo, i.e. situaciones en torno al individuo, dentro de sí mismo, que son accidentales (SL). ${ }^{31}$ Es posible distinguir el contraste de los "dos sabores de predicados SL e IL” en las siguientes oraciones tomadas de Gallego y Uriagereka (2009: 1):

(13) Obama $\{$ es $/ *$ está $\}$ estadounidense. ${ }^{32}$ Obama be-IL / SL.3.SG American

(14) Obama $\{*$ es / está $\}$ preocupado. Obama be-IL / SL. 3.SG worried

GMP (2015) proponen extender el valor explicativo de la distinción IL/SL al dominio de gradualidad (gradability). Su propuesta, argumentan, es compatible con el enfoque comparativo, y explican que los contrastes en oraciones como "Juan \{está borracho/*es alto $\}$ en la cocina", “Juan \{estaba borracho/*era alto $\}$ ayer" y "Juan era alto" vs. "Juan era borracho" pueden derivarse pragmáticamente de una inferencia de

\footnotetext{
${ }^{31}$ Fuente: Notas de clase, Profesor José Lema Labadie, "Sintaxis", nivel posgrado, trimestre 17-I, 7-9 febrero de 2017, Universidad Autónoma Metropolitana-Iztapalapa.

${ }^{32}$ En el original dice "americano".
} 
persistencia temporal ${ }^{33}$ que es accionada sólo por predicaciones con ser. De acuerdo con estos autores, dicha inferencia está vinculada con el carácter relativo o absoluto del complemento adjetival de la cópula, lo cual vuelve innecesario postular diferencias relacionadas con evento / aspecto / Aktionsart entre las predicaciones con ser y estar.

Desde 1992, en su artículo “Tiempo y Aspecto, correlatos sintácticos y semánticos: los auxiliares ser y estar", ${ }^{34}$ y más adelante, en 1995 en "Distinguishing copular and aspectual auxiliaries", ${ }^{35}$ Lema considera una distinción de tipo aspectual vs no aspectual entre ser y estar. Sugiere que el origen del contraste semántico en correlación con el uso de las cópulas en oraciones como: (a) Oscar es feliz/es alto (permanente), frente a (b) Oscar está feliz/está alto (limitado), radica en que ser es un simple elemento copulativo y estar es un auxiliar aspectual. Siguiendo a Bach (1967), Lema propone que no hay contenido aspectual en ser y explica que la propiedad permanente asociada a oraciones como las de (a) se entienden como un efecto de las propiedades temporales y no aspectuales de los elementos involucrados.

Estar como auxiliar tiene propiedades que lo identifican con ciertos verbos aspectuales del español como andar y seguir, que también seleccionan gerundios y adjetivos del tipo SL, a diferencia de ser.

(15) Pedro estálanda/sigue trabajando.

\footnotetext{
${ }^{33}$ Noción introducida por McNalky (1994) para dar cuenta del contraste entre predicados IL y SL en predicación secundaria (GMP, 2015: 136).

${ }^{34}$ En J. A. Pascual (ed.), Estudios Lingüísticos de México y España, Salamanca, Universidad de Salamanca, pp. $425-442$.

${ }^{35}$ En John Amastae, Grant Goodall, M Montalbetti y M. Phinney (eds.) (1995), Contemporary Research in Romance Linguistics: Papers from the 22nd Linguistic Symposium on Romance Languages, El Paso/Cd. Juárez, February 1992, John Benjamins, pp. 257-274.
} 
(16) *Pedro es trabajando.

(17) Pedro está/anda/sigue preparado para todo.

(18) *Pedro es preparado para todo.

Estos tres auxiliares tendrían una posición inferior a la del perfectivo haber, i.e. en una construcción de perfecto, haber aparece en primer lugar, después estar, y después ser, en caso de que sea progresivo, como en (19) y (20).

(19) Pedro ha estado/seguido/?andado siendo observado todo el tiempo por María.

(20) Pedro ha estado/seguido/andado siendo atolondrado.

En el nivel de la frase participial, el participio adquiere la denotación de un proceso, el cual permanece en toda la estructura, al contrario de las resultativas, donde el participio denotará un estado, ya no un proceso, debido al aporte aspectual de estar. Veamos un ejemplo con una pasiva en progresivo como en (34) Su cara está siendo alargada en la cirugía. La secuencia subrayada no implica necesariamente dos tipos de BE. Más bien, cabe diferenciar estos dos elementos, para lo cual utilizaré algunos argumentos presentados en Lema (1992) para definir que ser es una cópula sin carga semántica, como la del inglés y del francés, por ejemplo, mientras que estar es un auxiliar que aporta una interpretación aspectual. Por una parte, ser y estar aparecen en configuraciones de tipo atributivo estableciendo un contraste entre algo permanente y algo temporáneo.

(21) Miguel es feliz/alto. (permanente) 
(22) Miguel está feliz/alto. (temporáneo)

En francés est es el único elemento disponible para ambas construcciones, el cual, según Bach (1967), Stowell (1981), Chomsky (1992), entre otros, consideran desprovisto de contenido semántico cuya función es solamente la de soporte para marcas de Tiempo y Concordancia. Así en español, ser puede ser considerado como cópula, y estar como un auxiliar aspectual sintáctica y semánticamente similar al que aparece en las construcciones con gerundio (Lema, 1992). En el ejemplo de (21), el sentido de permanencia se puede ver como el reflejo del valor temporal de la oración (presente) y no de algún rasgo aspectual de ser; en (22) sí es estar el que añade la interpretación aspectual de temporalidad limitada.

Son varias las pruebas sintácticas que ofrece Lema (1992) para determinar las diferencias entre ser y estar. En primer lugar, ser tiene función identificativa o predicativa en construcciones como:

(23) a. Mi tía es la Sra. Martínez. (identificativa)

b. Mi tía es enfermera. (predicativa)

c. Mi tía está enferma. (predicativa)

Por su parte, estar sólo ocurre en función predicativa. Con la prueba sintáctica de Higgins (1979) establece esta diferencia: What para preguntas con predicativas y Who con identificativas (Lema(1992: 427-428):
a. ¿Quién es tu tía? - La Sra. Martínez.
b. ¿Qué es tu tía? - Enfermera. 
El auxiliar estar difiere de ser, ya que el segundo elemento de (23c) sólo puede cuestionarse por medio de elementos Qu oblicuos, operadores que ligan predicados.
a. ¿QQuién está tu tía?
- Enferma.

b. ¿Qué/Cómo está tu tía?/¿Tu tía está qué?

La segunda prueba sintáctica consiste en la anteposición de VP, que permite distinguir entre auxiliares aspectuales y no aspectuales. Según Akmajian, Steele y Wasow (1979), los verbos y auxiliares en inglés pueden anteponerse excepto cuando tienen contenido aspectual. Lema demuestra que sucede lo mismo en español. Véanse los siguientes ejemplos (1992: 428): ${ }^{36}$

(26) María dijo que estaban cocinando...
a. ...y cocinando (ellos) podían haber estado.
b. ...* y estando cocinando (ellos) podían haber.
c. ...* y haber estado cocinando (ellos) podrían.

(27) María dijo que habrían estado contentos...
a. ...y contentos (ellos) habrían estado sin duda.
b. ...*y estado contentos (ellos) habrían estado sin duda.

La posibilidad de anteponer el auxiliar ser en la pasiva acentúa la diferencia entre los auxiliares aspectuales y no aspectuales (Lema, 1992: 430):

(28) Dijo que ya habrían reparado las naves en la madrugada...

\footnotetext{
${ }^{36}$ Énfasis mío en (26b) y (26c).
} 

a. ...y reparadas ya habian estado siendo cuando llegamos.
b. ... y siendo reparadas ya habían estado cuando llegamos.
c. ... *y estado siendo reparadas ya habían cuando llegamos.

Como copulativo, también puede anteponerse ser, lo cual es una muestra más de su falta de contenido aspectual. Compárense (29) y (30).

(29) a. Los meseros sí que estaban siendo muy atentos debido al regaño.

b. Y siendo muy atentos sí que estaban los meseros debido al regaño.

(30) a. Los niños sí que habrían estado muy atentos de haber sido interesante la lección.

b. *Y estado muy atentos sí que habrían los niños de haber sido interesante la lección.

c. Y muy atentos sí que habrían estado los niños de haber sido interesante la lección.

Una prueba sintáctica más es la de coordinación, que, por una parte, permite establecer una conexión entre el auxiliar estar progresivo y estar perfectivo y, por otra, hacer una distinción más específica entre ser y estar. Véanse los siguientes ejemplos (Lema, 1992: 431-432):

(31) a. Era astuto y estaba listo (*inteligente/preparado) para correr.

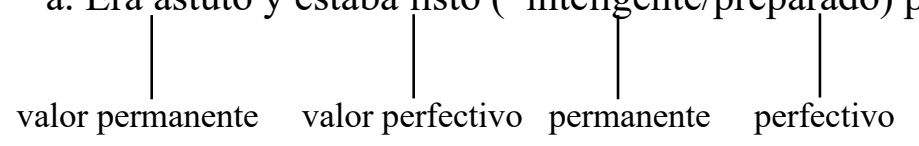


b. Era astuto y listo (inteligente/*preparado) para correr.

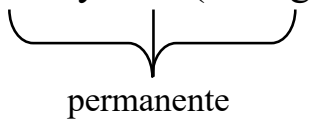

c. *Estaba listo y astuto para correr.

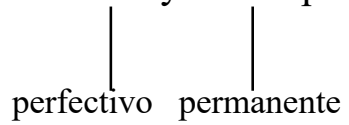

Al coordinar adjetivos perfectivos con gerundios progresivos, el auxiliar estar progresivo es suficiente para licenciar el valor perfectivo del adjetivo y excluye la lectura permanente:

(32) a. Estaba sonriendo y listo (*inteligente/preparado) para partir.

b. Estaba sentado y meditando acerca de las estructuras profundas.

c. *Era inteligente y meditando sobre las estructuras profundas.

Aquí Lema propone la posibilidad de considerar que estar perfectivo y progresivo son el mismo elemento, así que no bastaría con etiquetar estar como perfectivo, además de que las propiedades del auxiliar haber corresponden más cercanamente a la noción de perfectividad. Por eso, ahora lo considera simplemente como un auxiliar con un rasgo aspectual que puede ser "completado" con los rasgos ya sea perfectivo o progresivo, como se verá en el capítulo siguiente.

Por si estas pruebas sintácticas no fueras suficientes, hay dos más: la semejanza de estar con ciertos verbos aspectuales del español y la no presencia de estar como complemento de verbos de percepción. Véanse los siguientes ejemplos:

(33) Estar y verbos aspectuales seleccionan gerundios y adjetivos con valor limitado o perfectivo. 
a. Pedro está / anda / sigue trabajando.

b. *Pedro es trabajando.

c. Pedro ha estado / andado / seguido cansado.

Agrega que el auxiliar haber no introduce ni gerundios ni adjetivos y no tiene función atributiva, esto lo hace diferente del auxiliar estar. No obstante, los tres elementos aspectuales se encontrarán por encima de la cópula en atributivas y pasivas, como en:

a. Pedro ha estado /andado / seguido siendo cuidadoso.

b. Pedro está / anda /sigue siendo buscado por la policía.

Si combinamos estar con el verbo aspectual seguir, es prácticamente imposible que el primero domine a los otros aspectuales, lo cual lo reivindica como auxiliar:

(35) a. Pedro sigue estando listo para marcharse.

b. *Pedro está siguiendo listo para marcharse.

Por otra parte, Lema apunta que los verbos de percepción

[...] restringen las propiedades temporo-aspectuales de sus complementos: El evento perceptual y el evento percibido deben ser simultáneos. El Tiempo y Aspecto del verbo de percepción determinan el momento del evento denotado por el complemento. (Lema, 1992: 433)

En el siguiente ejemplo, “el momento del evento entrar está determinado por el de la percepción y le es simultáneo":

(36) Óscar vio / oyó / sintió a Pedro entrar por la puerta de atrás. 
Estar y haber, por su contenido aspectual, no pueden aparecer en el complemento.

(37) a. Su hermana vio a Óscar... (*estar) trabajando en la fábrica.

(*estar) dormido/listo.

b. *Su hermana vio a Óscar (haber) leído ese libro.

Los predicados con valor perfectivo o progresivo pueden aparecer sin el auxiliar. Los verbos de percepción son capaces de licenciar su propia presencia por sí solos. El perfectivo haber queda excluido debido a que este auxiliar sitúa eventos en un momento anterior al de referencia y entra en conflicto con la denotación del verbo de percepción. En contraste, ser sí puede aparecer como complemento de este tipo de verbos:

(38) a. Su hermana vio a Óscar ser más cuidadoso que nunca.

b. Su hermana vio a Óscar ser trasladado al penal.

c. *Su hermana vio a Óscar estar siendo trasladado al penal.

d. Su hermana vio a Óscar siendo trasladado al penal. ${ }^{37}$

Las construcciones con participios donde éstos denoten meros estados, es decir, no tengan naturaleza verbal en su derivación. Por ejemplo, la oración Su sonrisa es apagada no implica un proceso de apagado de la sonrisa, i.e. puede interpretarse como una característica innata de la sonrisa de alguna persona, no necesariamente que antes era encendida y que se apagó, por así decirlo. Estos participios son llamados adjetivales dadas las características que comparten con los adjetivos, como el hecho de ocupar la misma

\footnotetext{
${ }^{37}$ Los ejemplos (38c) y (38d) son míos.
} 
posición en construcciones con estar "(Juan está borracho/preocupado), como predicativos adjuntos (Llegó a su casa borracho/preocupado) o en construcciones absolutas o introducidas por con (Con el jefe borracho/preocupado, no se trabaja igual)". (Marín, 2009: 327). ${ }^{38}$ Señala Marín que los cambios de acepción, es decir, los participios que además de la acepción verbal poseen una adjetival, son casos interesantes. Las oraciones en las cuales el participio es categorizado como adjetivo son llamadas estativas en la presente investigación.

Lázaro Carreter (1975) había analizado ya las asimetrías entre atributivas y pasivas. Por una parte, el eje paradigmático de los adjetivos y de los participios en estas construcciones es distinto. Compárense (39) y (40).

(39) La tirada fue reducida/disminuida/acortada por el editor.

(40) La tirada fue reducida/corta/escasa por el carácter minoritario de la edición.

Para aclarar las distintas interpretaciones basta con considerar la FP de (39) como el agente (o argumento externo) de los participios en cuestión, por lo tanto, sólo se permiten participios verbales en la estructura. En (40), la FP se refiere al motivo por el cual la tirada tuvo esa característica, es decir, por implica debido a ello. Cabe mencionar aquí que la FP de causa/agente en las pasivas es adyacente al participio y no ser, lo cual se comprueba con la pronominalización de (i) Fue multado por el gobernador. = Lo fue; o de (ii) La tirada fue reducida/disminuida/acortada por el editor. $=$ Lo fue.

Por otra parte, la pasiva acepta el modificador adverbial mucho, mientras que la atributiva o adjetival aceptaría muy antes del adjetivo.

\footnotetext{
${ }^{38}$ Fronteras de un diccionario: las palabras en movimiento / Elena de Miguel (aut.), Santiago U. Sánchez Jiménez (aut.), Ana Serradilla Castaño (aut.), Romana Anca Radulescu (aut.), Olga Batuikova (aut.), 2009, págs. 327-348.
} 
(41) La tirada fue reducida mucho por el editor.

(42) La tirada fue muy reducida (debido a los costos).

En las construcciones con ser y estar presentadas en esta investigación precisamente es esa cuestión la que nos interesa: ¿cómo se derivan los participios que puedan aparecer en construcciones pasivas y resultativas?

Si comparamos las oraciones en pasiva del capítulo 1, con las resultativas del capítulo 2 y las siguientes oraciones, se observa que la interpretación semántica del participio será diferente en cada una:

(43) Las luces son apagadas. (pasiva eventiva)

(44) Las luces están apagadas. (resultativa estativa)

(45) Sus ojos son apagados. (adjetival permanente)

(46) Sus ojos están apagados hoy. (adjetival perfectiva)

En (43) hay un proceso en el que las luces están encendidas y las apaga un agente implícito. En (44) se denota el estado resultante de un proceso como el de (1) delimitado por la contribución aspectual de estar. En (45) no hay un proceso inferido: pensemos en que una persona nació así, con los ojos sin vida, como tristes. El uso de estar en (46) refleja cierta delimitación de lo denotado por el participio, lo cual se hace más evidente con el adverbio hoy: normalmente no se encuentran en ese estado, pero temporalmente así están. Los participios en (45) y (46) al no indicar un evento, sino una característica del individuo, no se derivará a partir de una $\mathrm{v}$ pequeña. 


\section{Capítulo 2: Resultativa}

\section{¿Qué es una resultativa?}

Las formas resultativas pueden considerarse estados secundarios o derivados si se piensa que son consecuencia de la acción consciente de alguien, en otras palabras, mantienen una relación unidireccional con las de perfectivo: Pedro ha roto el cable $\rightarrow$ el cable está roto; o resultan de algún cambio: María ha bebido mucho $\rightarrow$ sus ojos están enrojecidos. Frente a los estados resultantes existen los naturales o primarios, que no implican a un agente ni proceso previo (como joven, liso, nuevo, etc.).

Rodríguez-Espiñeira y Peña (2011: 194-195) explican, además de lo expuesto en el primer párrafo, que, en las construcciones resultativas, los participios "fácilmente dan acceso al proceso previo", aunque de la forma resultativa no se deduce lingüísticamente el nombre del evento previo, ni se establece una equivalencia mecánica entre esa construcción y la forma de perfecto correspondiente. Agregan que la negación de una resultativa genuina supone la ausencia tanto del estado final como del proceso previo. En español es $<\sin +$ infintivo>. Compárense Este recipiente está calentado frente a Este recipiente esta sin calentar o El estanque está limpiado versus Aquel estanque está sin limpiar.

En la literatura, las construcciones resultativas han sido descritas de las siguientes formas, todas con la implicación de un proceso previo:

(a) Construcciones con participios que denotan un estado resultante de un evento (Embick, 2004).

(b) La construcción resultativa se centra en un estado actual (el evento que implica llegar a ese estado se infiere) (Mittwoch, 2008). 
(c) Formas verbales que expresan un estado el cual implica un evento previo (Nedjalkov \& Jaxontov, 1988).

(d) Cualquier expresión de un estado con algún rastro formal de dinamicidad y/o anterioridad que refleje la posibilidad de un evento previo (Wälchli \& Olsson, 2012).

Wälchi y Olsson (2012) explican que en estudios translingüísticos las resultativas pueden ser de dos tipos. Puede hacerse una distinción en términos vendlerianos (1967) de acuerdo con las categorías verbales aspectuales como resultativas estativas y resultativas de logro (accomplishment). Por ejemplo, en letón (1) y (2) respectivamente:

$\begin{array}{lll}\text { Sien-a } & \text { ir } & \text { no-krāso-t-a. } \\ \text { wall-NOM.F.SG } & \text { be:PRS3 } & \text { PV-paint-PTC.PST.PASS-NOM.F.SG }\end{array}$

'The wall is painted.'/ 'La pared está pintada'.

$\begin{array}{llll}\text { Jānis } & \text { no-krāso-ja } & \text { sien-u } & \text { zil-u } \\ \text { Janis } & \text { PV-paint-PST3 } & \text { wall-ACC.F.SG } & \text { blue-ACC.F.SG }\end{array}$

'John painted the wall blue.' / 'Juan pintó la pared de azul'.

Nedjalkov \& Jaxontov (1988: 6, citado en Wälchi y Olsson, 2012) definen las resultativas estativas como "formas verbales que expresan un estado que implica un evento previo". Una resultativa de este tipo sería cualquier expresión de un estado con un rastro formal de dinamicidad y/o anterioridad reflejando un evento previo potencial, no necesariamente real. Mencionan que incluye la estrategia de verbo transitivo en construcción intransitiva, con el siguiente ejemplo en lengua kobon de Nueva Guinea, el 
cual es una perfecta instancia de la derivación propuesta para los participios en esta investigación:

$\mathrm{Ru} \quad \mathrm{pa} \quad \mathrm{jö} \quad \mathrm{g}$-öp

axe strike break do-PERF3SG

'The axe is broken'. / 'El hacha está rota'. (Davies 1981: 163)

Bybee, Perkins y Pagliuca (1994: 67-68, citado en Wälchi y Olsson, 2012) señalan que "en el caso más común, el sentido resultativo viene de la combinación del auxiliar estativo, que proporciona la noción de un estado presente, y el participio pasado y/o pasivo, que apunta a una situación dinámica que ocurrió en el pasado y que se considera que afecta al objeto del verbo transitivo o al sujeto del intransitivo".

Bosque (2014) divide los participios del español como se muestra en (4). No presenta divisiones para los adjetivales y los eventivos porque lo único que le concierne en esa investigación son los resultativos.

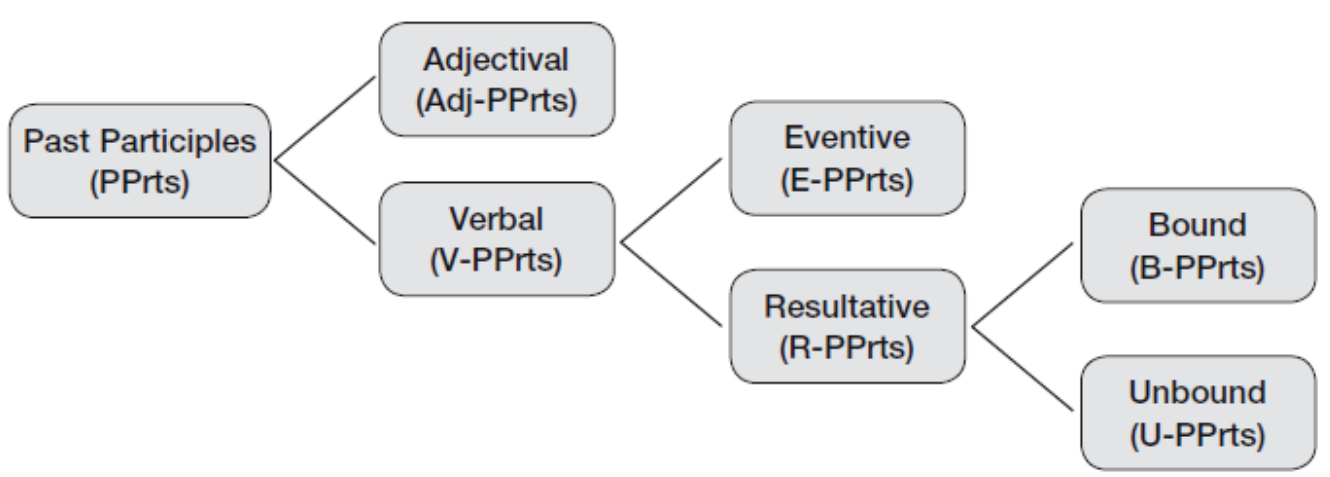

Fuente: Bosque (2014: 44)

Explica que se trata de una división léxica que depende de las propiedades aspectuales de los verbos de los que se derivan estos participios. Como rasgos semánticos, 
bound refiere al sentido de que el evento denotado tiene límites, i.e. el evento mismo denota un inicio y un fin simultáneos, y unbound, a lo contrario, se permite una interpretación de continuidad o mayor duración del evento. Bosque asume el análisis estándar ${ }^{39}$ según el cual los participios se derivan de verbos que tienen sus argumentos internos explícitos, lo cual incluye a los transitivos y a los inacusativos, excluyendo a los inergativos, aunque centra su análisis solamente en los transitivos (Bosque, 2014: 52).

a. B-PPrts derivados de verbos transitivos:

un niño castigado; ladrones atrapados por la policía; aviones derribados por el enemigo; un trabajo terminado.

b. U-PPrts derivados de verbos transitivos:

un edificio vigilado; una ciudad rodeada de montañas; un libro acompañado de un $C D$; un apartamento habitado por recién casados.

Respecto a los derivados de inacusativos, habla de la ambigüedad en relación con el verbo del que pueden derivarse, ya sea de un transitivo o de un incoativo:

a. B-PPrts derivados de verbos inacusativos: un barco hundido; un joven enamorado; una pareja separada.

b. U-PPrts derivados de verbos inacusativos: acusaciones basadas en hechos; gente empeñada en molestar; un capitel apoyado en una columna.

Si bien su análisis se enfoca principalmente en estos participios contenidos en frases nominales, puesto que su objetivo es argumentar a favor de que dichos participios son

\footnotetext{
${ }^{39}$ Literal, así lo expresa el autor.
} 
verbales y no adjetivales, no puede evitar mencionar el auxiliar estar, que dice, ha sido tradicionalmente asociado con la noción de resultado. Comienza mencionando la pregunta tradicional de si las construcciones estar + participio son pasivas reales, y descarta la utilidad de esta pregunta, incluso para las construcciones ser + participio, dado que las construcciones sintácticas son expresiones composicionales: los rasgos del elemento léxico son los que darán cuenta de sus propiedades semánticas y sintácticas. Más bien, hay que reformular la pregunta: ¿bajo qué circunstancias estar selecciona un participio verbal? (Bosque, 2014: 66). La vieja respuesta de Gili Gaya (1943), dice Bosque, es que los participios verbales aceptados por estar expresan el resultado de una acción terminada. Agrega que diversos análisis en este sentido han predicho correctamente que los participios derivados de verbos que no denotan acción rechazarán estar, como temido, odiado, conllevado, preferido. Otra predicción correcta, agrega, es el hecho de que las lecturas activas de verbos estativos pueden admitir construcciones con estar. Compárense (7) y (8) (Bosque, 2014: 67, n.p.24).

a. ??El paisaje está mirado desde el balcón.

b. ?*El dinero está poseído por Juan.

a. El asunto está mirado con objetividad en ese artículo.

b. Juan está poseído por el dinero.

No obstante, aclara, una predicción incorrecta es que los participios verbales que no denotan resultado no aceptarán estar. Bosque cita a Marín (2000) y a Jiménez \& Marín (2002) quienes toman una interpretación restrictiva de dicha noción y asumen que los eventos limitados incrementales (incremental bounded events) que no denotan resultado, 
rechazan estar. Bosque refuta esto con ejemplos tomados de internet que además puso a prueba con hablantes nativos y fueron aceptados, como El puente ya estaba cruzado, y una sala llena de piscinitas con distintos; Lo curioso es que nunca tuvo mucho interés en hablar de la obra, solo quería asegurarse de que estaba leída por mí; El recital de anoche estuvo interpretado por el prestigioso Cuarteto Quiroga. ${ }^{40}$

No hay duda que los ejemplos y argumentos proporcionados por Bosque aclaran el sentido de estas construcciones pero, más que hablar de qué tipo de participios aceptan estar, ya que implicaría hacer una división en términos de aspecto léxico, la cual daría lugar a excepciones, pues es casi imposible hacer divisiones tajantes al respecto, en el presente capítulo se estudiarán las construcciones del tipo resultativa estativa estar + participio, proponiendo que la derivación del participio será a través del elemento verbalizador vio y la contribución aspectual perfectiva de estar será la que permita la interpretación del estado resultante, más que del proceso denotado por el participio solo. Para tal fin, comenzaré con los tipos de verbos en estas construcciones y ejemplos de resultativas en español; después, propondré una estructura de derivación sintáctica que puede dar cuenta de cómo se denotan los estados resultantes en este tipo de construcciones.

\footnotetext{
${ }^{40}$ Nótese que la frase preposicional por $X$ le sigue al participio en dos de estos ejemplos.
} 


\section{Tipos de verbos en resultativas en español}

$\mathrm{Al}$ igual que las pasivas eventivas, los verbos aceptados en las resultativas son aquellos que se derivan de un elemento $\mathrm{V}_{\mathrm{DO}}$ para denotar el proceso (o evento) previo al estado resultante. En el capítulo anterior, se explicó que los verbos derivados de $\mathrm{v}_{\mathrm{DO}}$ permiten un argumento Tema (interno) y un Sujeto Agente (argumento externo). Derivados de $\mathrm{v}_{\mathrm{GO}} \mathrm{y} \mathrm{v}_{\mathrm{BE}}$ cuyo único argumento es Tema, no pueden formar ni pasivas eventivas, ni resultativas:

(9) El niño es medido por la enfermera antes de su consulta médica.

(10) Este niño ya está medido, así que ya puede pasar con el doctor.

(11) *El árbol es caído.

(12) *Este árbol ya está caído.

(13) *Joaquín es faltado a clase. / *La clase es faltada por Joaquín.

(14) *Joaquín ya está faltado a clase. / *Esta clase ya está faltada por Joaquín.

En (9) se trata de una pasiva eventiva con participio derivado de $\mathrm{v}_{\mathrm{DO}}$, mientras que en (10) tenemos una resultativa con participio igualmente derivado a partir de $\mathrm{V}_{\mathrm{DO}}$. Esto explicaría los verbos estativos con lecturas activas, como en los ejemplos de (7) y (8): en su lectura estativa se derivan a partir de $\mathrm{v}_{\mathrm{BE}} \mathrm{y}$ en su lectura activa de $\mathrm{v}_{\mathrm{DO}}$. Lo que comparten las construcciones estar + participio analizadas en este capítulo es la denotación de un proceso que se da en la formación del participio dentro de la Frase Participial. La diferencia entre pasivas eventivas y las resultativas estativas radica en el uso de ser en la pasiva, que no cambiará la interpretación del proceso, mientras que estar en la resultativa va a propiciar 
que lo denotado sea el estado resultante de dicho proceso o evento previo, gracias a la perfectividad expresada por el auxiliar.

En (11) y (12), debido a que el participio se deriva a partir de una v pequeña de tipo $\mathrm{V}_{\mathrm{GO}}$ - i.e. denota un cambio de estado del argumento interno - no puede aparecer en una construcción pasiva ni resultativa. Respecto a los ejemplos en (13) y (14), por tratarse de una derivación a partir de $\mathrm{v}_{\mathrm{BE}}$-i.e. denotan un estado-, tampoco ocurren en construcciones pasivas ni resultativas.

\section{Ejemplos de resultativas en español}

Las siguientes oraciones son una versión resultativa de las pasivas eventivas del capítulo 1:

(15) Las luces están apagadas.

(16) Las opciones ya están reducidas (ahora tendrán que pensarlo mejor).

(17) El jefe ya está informado de lo acontecido.

(18) Su cara está alargada gracias a la cirugía.

(19) El gato ya está divertido con la bola de estambre que le dimos, así que no nos molestará más.

(20) La gente está alocada después de las elecciones.

En algunos de los ejemplos se nota la presencia, casi obligatoria, de ya, que puede considerarse como una especie de marcador de la finalidad del proceso denotado por el participio, ${ }^{41}$ y que si bien es opcional, en ciertos casos pareciera necesario para la

\footnotetext{
${ }^{41}$ La tercera acepción en el Diccionario de la Real Academia Española es: "adv. En el tiempo presente, haciendo relación al pasado. Era muy rico, pero ya es pobre" [consultado en línea], y esto es justamente lo
} 
denotación completa de una resultativa en español. Por esta razón lo incluyo en los ejemplos cuya lectura de resultativa podría no ser tan evidente.

Bosque explica brevemente que esto corresponde a la interpretación estándar de resultativa de perfecto.

a. Las maletas (ya) están listas.

b. Las maletas (ya) están hechas.

c. El periódico de hoy (ya) está leído.

Resalta como interesante que la posibilidad de omitir ya rara vez es mencionada en la literatura sobre este adverbio. Nótese que puede ser omitido en los ejemplos (21b) y (21c) y en el ejemplo obtenido de internet Lo curioso es que nunca tuvo mucho interés en hablar de la obra, solo quería asegurarse de que estaba leída por mí, no está presente. Dice Bosque que si simplemente tomamos a los participios como denotadores de estados de nivel de estadio (SL) resultantes de acciones o procesos, nos perderemos de este factor extensional en su interpretación. La pregunta según este autor es ¿cómo hace el participio para proporcionar el significado que agrega el adverbio de fase ya? Bosque sugiere que en los participios resultativos hay un haber escondido (de perfecto) en estos participios (Bosque, 2014: 69-70), la propuesta de esta investigación es que es el auxiliar estar el que agrega el sentido de perfectividad a la estructura y se puede prescindir del adverbio, y cuando hay ambigüedad o contraste o es necesario aclarar cuando el hablante quiere expresar una resultativa, lo agregaría, especialmente con verbos con más de una interpretación.

que expresa una resultativa, es decir, se hace alusión al pasado con la inferencia del proceso previo al estado denotado en tal estructura. 
(22)

a. Un chef oliendo las sopas de sus asistentes:

“Esta sopa $y a$ está olida y probada, está perfecta jsale!”

(Esa sopa ya, las otras todavía no)

b. ¿Cómo vas con la tesis?

- Pues está leída.

¿Cómo?

- Sí, ya está leída por mi asesor y mis lectores, pero sigo esperando sus comentarios puntuales.

\section{Derivación sintáctica de una resultativa}

La derivación sintáctica de una resultativa puede ser representada de la siguiente manera. En el primer momento de fusión, se encuentran la raíz y su argumento interno, cuya concordancia será materializada en el nodo -d-, es decir, con el morfema de participio.

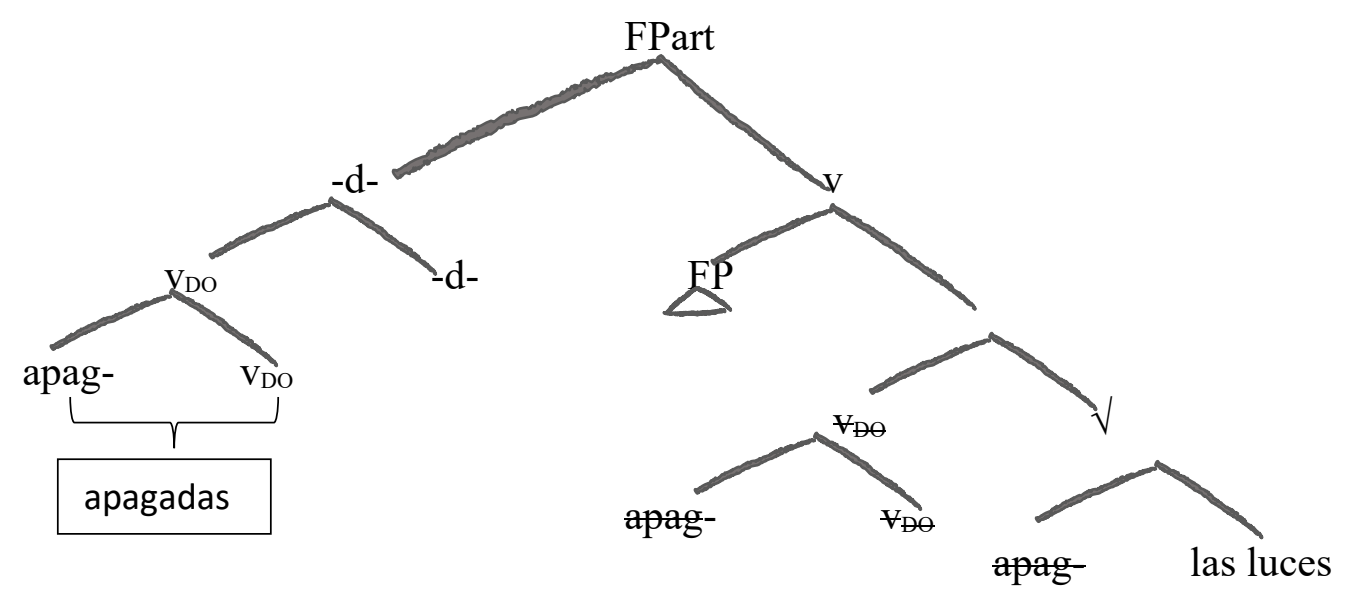


En este punto es importante poner atención a la posición del complemento agente que permanece en su lugar, tal como en las pasivas eventivas del capítulo 1, dado que es permitido por el tipo de verbalizador. De acuerdo con Navas Ruiz (1987: 51, citado en Conti-Jiménez, 2004: 27) estar permite la presencia del SP-por cuando la actuación del agente tiene que continuar para que persista el estado al que se refiere la acción como en $E l$ camino está cortado por los manifestantes. Por su parte, Gómez Torrego (1988: 188, citado en Conti-Jiménez, 2004: 27) establece una pasiva imperfectiva con estar, que admite con normalidad el complemento agente (El garaje está vigilado por el guarda=El garaje está siendo vigilado por el guarda), y una pasiva perfectiva estativa con estar, que con poca frecuencia acepta la aparición del SP-por (El precio está fijado). ${ }^{42}$ No obstante, el agente está presente subyacentemente en estos eventos previos al estado resultante denotado en toda la estructura. Ya sea que se materialice o no, el agente está en la estructura. En la representación de las derivaciones la propongo siempre como una FP en posición de especificador de v.

Volviendo a la derivación presentada en (23), en la Frase Participial se denotará el evento-proceso apagadas las luces. Nótese que el argumento interno podría borrarse de esa posición y copiarse como especificador de C, pero también podría permanecer in situ; así, en el spell-out la construcción puede ser: Las luces están apagadas o Están apagadas las luces, dependiendo de factores pragmáticos, según el contexto de enunciación.

Antes de presentar la representación arbórea completa de una oración resultativa estativa es necesario exponer los rasgos aspectuales del auxiliar. En (24) tenemos un nodo aspectual con el rasgo $<$ asp $>$ no interpretable y un nodo perfectivo con el rasgo aspectual

\footnotetext{
${ }^{42}$ El precio está fijado ?por el gerente.
} 
$<$ perf $>$ interpretable. El primero requiere ser valorado por el segundo, y una vez checado y borrado, se materializará en el nodo Tiempo como estar $+T$ (están, estuvieron, estaban, etc.).

(24) Posición y rasgos de estar

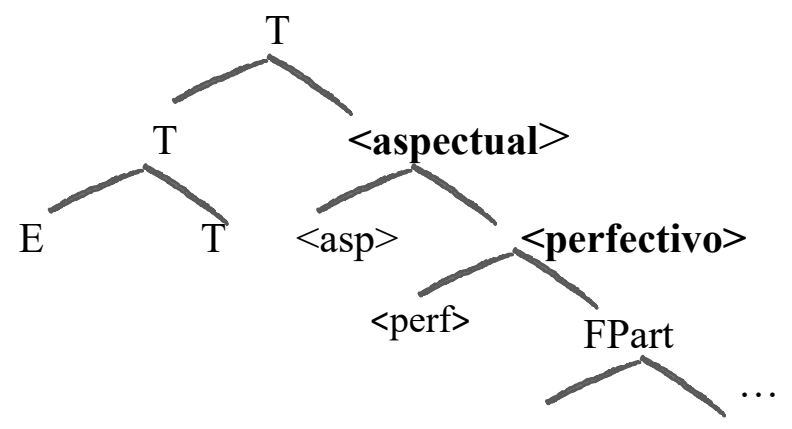

(25) Derivación de Las luces están apagadas.

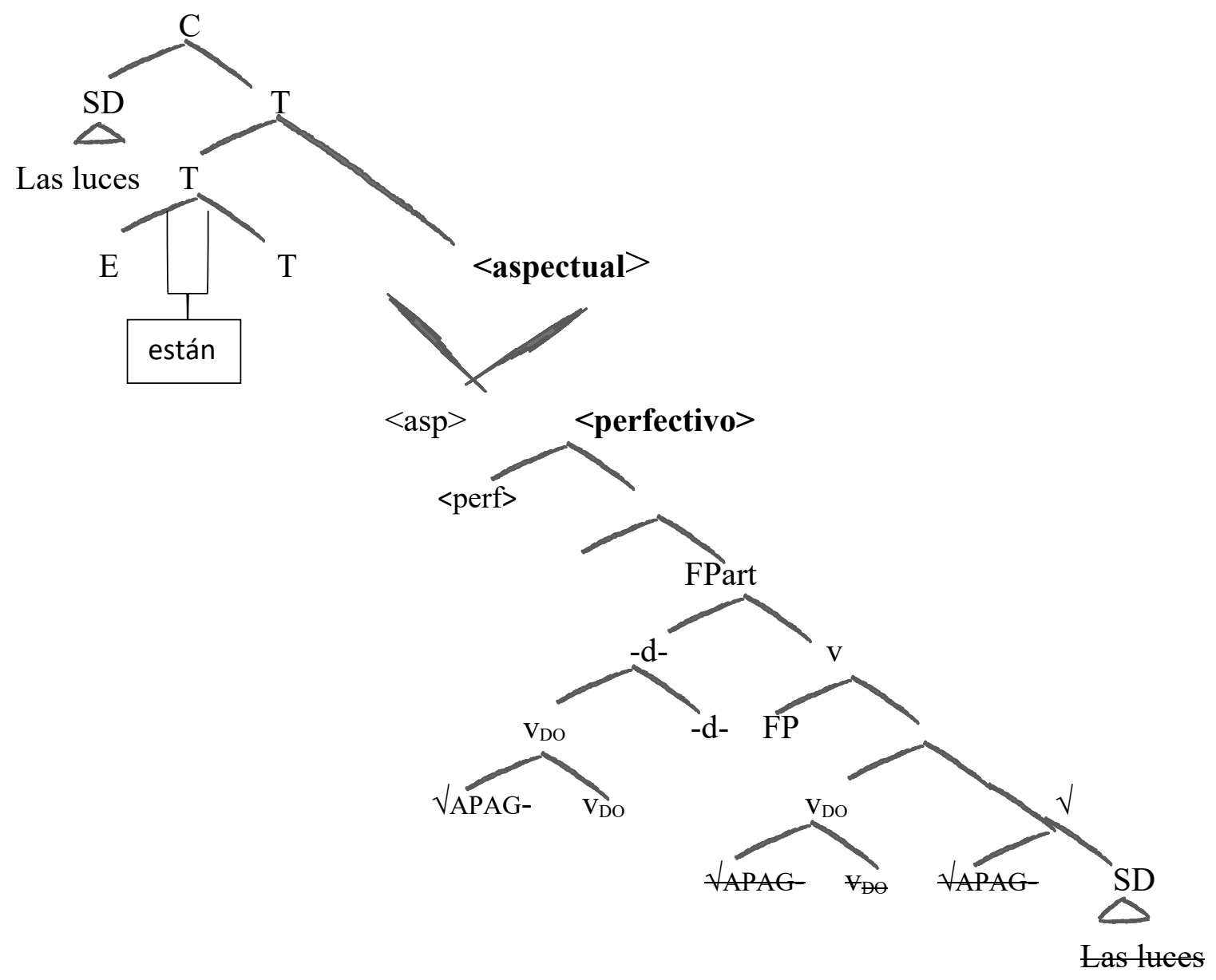


El espacio entre FPart y < perfectivo $>$ no va a materializarse en spell-out, a menos de que sea necesario, por ejemplo, para poder formar pasivas progresivas como Las luces están siendo apagadas una por una. Recordemos que los rasgos aspectuales de estar son de dos tipos: progresivo o perfectivo. El primero tendrá contenido fonético, como se explicó en la derivación de una pasiva progresiva en el diagrama (44) del primer capítulo, como el morfema -ndo. El rasgo apectual de perfectivo no tiene contenido fonético, así que no saldrá a spell-out como ningún morfema, pero quedará implícito en la estructura subyacente. En una resultativa, como la de (25), tendremos un rasgo aspectual no interpretable (uAsp) y el rasgo <perfectivo> interpretable, los cuales, una vez checados serán los que bloquean la denotación del proceso denotado en la Frase Participial para expresar el estado resultante.

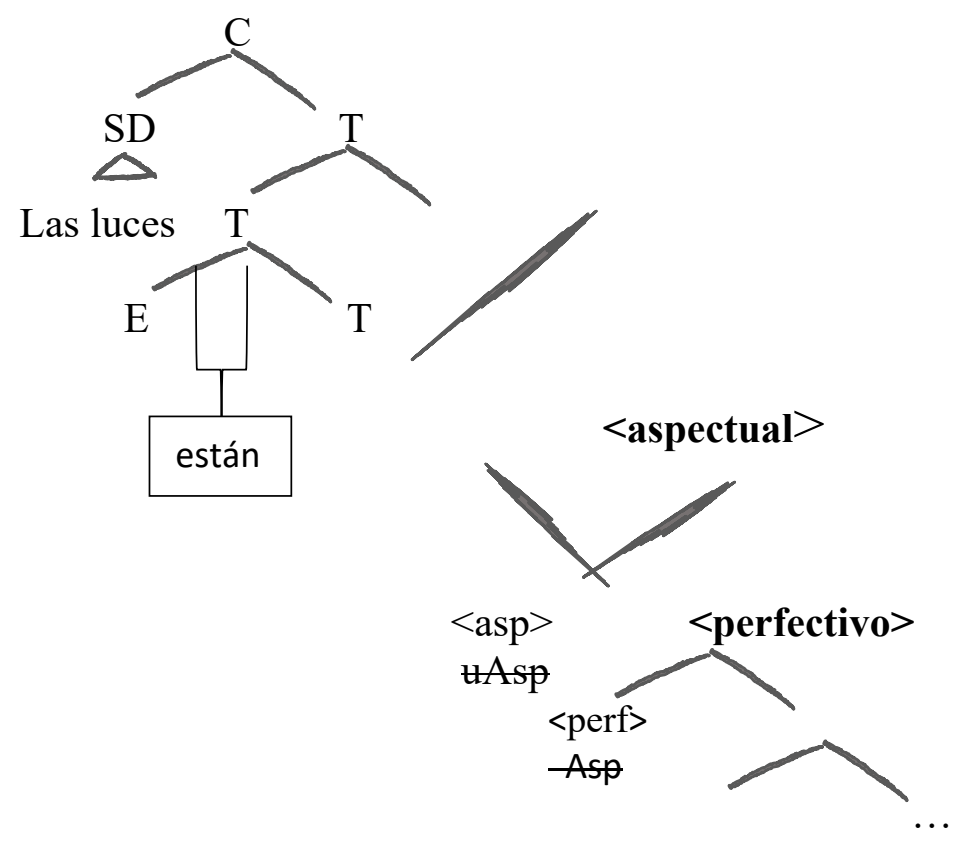


En resumen, en las pasivas ser es obligatorio para que se materialice el Tiempo y no contribuye aspectualmente en una oración de este tipo. En una pasiva eventiva progresiva, con estar se materializa el Tiempo y con ser, el sufijo -ndo exigido por el aspecto progresivo de estar (véase 27). Para ello se requiere el auxiliar con aspecto progresivo estar, el cual, a su vez, requiere el sufijo -ndo anclado al siguiente elemento de la estructura. Como el participio no acepta más afijos, ahí se inserta ser, esta vez como soporte para el gerundio.

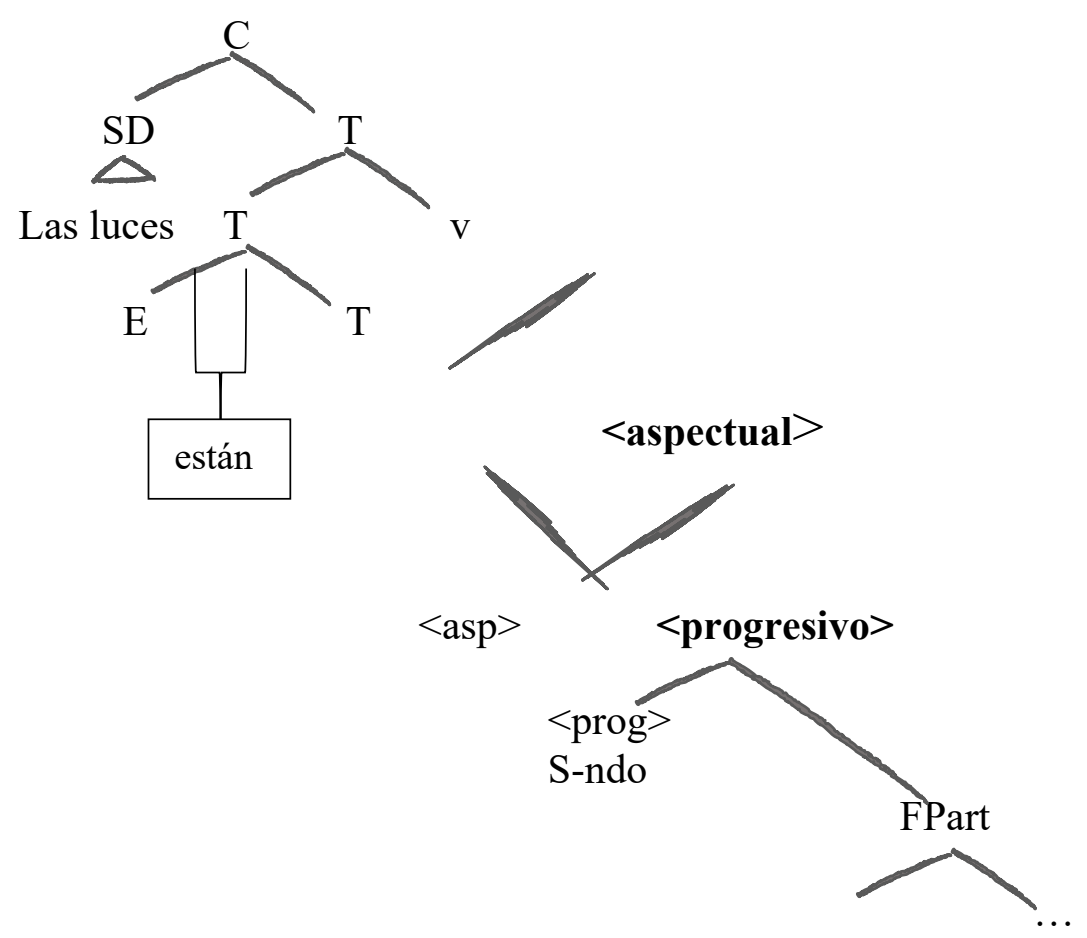

En las resultativas, estar es necesario para la materialización del Tiempo y además agrega un significado aspectual de perfectividad. En estas construcciones no es necesario que se materialice ser. Véanse los siguientes ejemplos:

(28) Las luces fueron/serán/han sido apagadas.

(29) Las luces están siendo apagadas.

(30) Las luces están/estaban/estuvieron apagadas. 


\section{Conclusiones}

En esta idónea comunicación de resultados se han presentado argumentos para considerar que los participios que ocurren en construcciones con ser y estar del español no contienen el rasgo aspectual de perfectividad, i.e. no son participios de pasado ni de perfecto, y que pueden ser derivados verbales o simples adjetivos. Nos hemos enfocado en aquellos derivados a partir de un tipo particular de elemento verbalizador, normalmente denominado $\mathrm{v}$ pequeña, a saber, $\mathrm{v}_{\mathrm{DO}}$, que además de su argumento interno, permite una cabeza funcional para el argumento externo - agente o causa-, lo que a su vez permite que dichos participios aparezcan en construcciones de pasiva eventiva y de resultativa estativa.

En el primer capítulo se definió que la construcción de pasiva eventiva es aquella en la cual el verbo, que denotará un proceso y cuyo argumento interno es un Tema, se deriva por medio de un elemento verbalizador, el cual a la vez permitiría la introducción de un argumento externo, siempre presente en la estructura subyacente, que a veces se materializa en la forma fonética como FP adjunta "por + SD". Las pasivas eventivas de esta investigación consisten en un auxiliar y un participio, ambos en concordancia de número con sujeto oracional, el participio también de género, y con la marca de tiempo en el auxiliar. Asimismo, se estableció que uno de los mecanismos por medio de los cuales se obtiene una construcción pasiva de este tipo consiste en la "omisión" del argumento externo, y no se aplica cuando éste no es proyectado e identificado subyacentemente. En los verbos inacusativos al no estar presente este componente, no es posible formar pasivas. Ahora bien, aunque en las pasivas el agente está "ausente", de cierto modo se encuentra presente semánticamente ya que está en la estructura subyacente, aunque no se materialice 
en la forma fonética. El verbalizador de tipo $\mathrm{v}_{\mathrm{D} O}$ permite que el verbo cuente con este argumento y por tanto, permite la formación de pasivas.

Antes de pasar a las construcciones resultativas, se presentó un interludio con el fin de aclarar algunas diferencias entre los elementos ser y estar. En general, se corroboraron las propiedades de ser como cópula y las características de estar como auxiliar aspectual. En las construcciones pasivas eventivas el auxiliar ser no tiene ningún contenido aspectual por lo cual si la derivación del participio a partir de la v pequeña con sabor a v la denotación de un proceso, ésta se mantiene al materializarse toda la estructura: La tesis es escrita por las tardes expresa el proceso de escritura llevado a cabo, en este caso, con habitualidad en cierto momento del día. Si el participio derivado a partir de VDo aparece con aspecto perfectivo, la noción de proceso contenido en la frase participial es bloqueada, lo cual da lugar a la interpretación del estado resultante: La tesis está escrita al fin implica que en ese estado se encuentra la tesis, escrita, i.e. ya terminada, el archivo quedó listo o incluso impreso en papel. Estar contiene un rasgo aspectual no interpretable, el cual, para ser valorado, es necesario que en la secuencia sintáctica haya un rasgo progresivo o uno perfectivo.

Entonces, las formas resultativas de este tipo pueden ser consideradas como estados secundarios o derivados si se piensa que son consecuencia de la acción consciente de alguien: La tesis está escrita implica que alguien la escribió. Según Rodríguez-Espiñeira y Peña (2011), la negación de una resultativa genuina supone la ausencia tanto del estado final como del proceso previo: en español es <sin + infintivo>; compárense El estanque está limpiado versus Aquel estanque está sin limpiar. ${ }^{43}$ Las resultativas del español aquí

\footnotetext{
${ }^{43}$ Considero aceptable el contraste Esta tesis está escrita $\sim$ Esta tesis está sin escribirse/sin ser escrita/?sin escribir.
} 
tratadas se diferenciaron de las resultativas típicas del inglés que abundan en la literatura, como John painted the wall blue, clasificándolas como resultativas estativas, que refieren a formas verbales que expresan un estado que implica un evento previo. Una resultativa de este tipo sería cualquier expresión de un estado con un rastro formal de dinamicidad y/o anterioridad reflejando un evento previo potencial.

No sólo se habló de la lectura de pasiva y de resultativa de una estructura con ser/estar + participio, también se mencionó la lectura atributiva, en la cual el participio funciona como un adjetivo, y la elección de ser o estar en este tipo de construcciones predicativas dependerá de lo que se quiera denotar: un estado permanente o temporario, compárese Miguel es distraído (característica inherente al individuo, permanente) frente a Miguel está distraído (en este momento, se distrajo por un rato).

En conclusión, el hecho de que una estructura sintácticamente idéntica tenga diferentes posibilidades de ser interpretada puede ser explicado mediante la distinción de los elementos que intervienen en la derivación de cada una de sus partes. La construcción ser + participio puede tener dos lecturas: una de pasiva eventiva (1a), otra de atributiva (1b). La construcción estar + participio igualmente puede tener dos lecturas: la de resultativa estativa (2a) o la de una atributiva $(2 b)$.

(1) a. Refugio es callada por sus compañeros a cada rato. Habla mucho.

b. Martha es callada. No le gusta hablar mucho.

(2) a. Refugio (ya) está callada. Todos sus compañeros le insistieron tanto que dejara de hablar que al fin se calló.

b. Refugio está muy callada hoy. ¿Estará triste? 
¿Cómo es posible que un hablante haga estas cuatro distinciones en la interpretación de un elemento con la misma forma en todas ellas? Esto se explica por cómo se lleva a cabo la derivación del participio: en (1a) involucra un elemento verbalizador $\left(\mathrm{v}_{\mathrm{DO}}\right)$ que permite entender que calla- $d$ - $a$ implica un proceso donde alguien calla a Refugio, sea este agente materializado en el habla o no; en (1b) no está presente dicho verbalizador, calla- $d$ - $a$ es un atributo del individuo del que se predica; en (2a) calla- $d$-a también se deriva a través de una v pequeña que indica que hubo un proceso mediante el cual alguien calló a Refugio y ahora se encuentra en ese estado; en (2b), sin el verbalizador presente en la derivación sintáctica de calla-d-a, ${ }^{44}$ el hablante interpreta que es un atributo de Refugio, pero no permanente, normalmente Refugio no es así.

Respecto al papel de ser en (1a), se concluye que se trata de un elemento que simplemente va a ser el soporte de Tiempo y de Concordancia con el sujeto oracional. Semánticamente no aporta nada. El proceso denotado por el participio se mantiene. En (1b) es una cópula, i.e. un mero enlace entre el individuo y una característica permanente de éste. Por otro lado, estar aporta un sentido aspectual en (2a) y (2b): en (a), la fusión $\{\{<$ Asp $>\}\{<$ Perf $>\}\}$ corta el proceso de callar a Refugio denotado en el participio y da pie al inicio del estado resultante de dicho proceso al delimitarlo aspectualmente; mientras que en (b) delimita la característica de ser callada a un momento o periodo de tiempo específico. Aunque hay mucho que detallar respecto a estas construcciones y cada uno de sus elementos, se espera que los resultados de esta investigación sean un aporte más que ayude a descifrar cómo funciona nuestra facultad del lenguaje.

\footnotetext{
${ }^{44}$ Podríamos incluso hablar de una a pequeña como elemento adjetivizador, que a su vez, debería ser de distintos sabores puesto que hay adjetivos de diversos tipos, lo cual sería material para futuras investigaciones.
} 


\section{Abreviaturas}

\begin{tabular}{|c|c|}
\hline $\mathrm{ACC}$ & Acusativo \\
\hline Agte & Agente \\
\hline Aux & Auxiliary \\
\hline B-PPrts & Bound Participles \\
\hline $\mathrm{C}$ & Complementante \\
\hline Caus & Causador \\
\hline DP & Determiner Phrase \\
\hline $\mathrm{E}$ & Estar \\
\hline $\mathrm{F}$ & Femenino \\
\hline FN & Frase Nominal \\
\hline FP & Frase Preposicional \\
\hline FV & Frase Verbal \\
\hline $\mathrm{H}$ & Haber \\
\hline IL & Individual Level \\
\hline Init & Initiator \\
\hline $\mathrm{N}$ & Noun/Nominal \\
\hline NOM & Nominativo \\
\hline NP & Noun Phrase \\
\hline $\mathrm{P}$ & Preposición \\
\hline PASS & Pasiva \\
\hline PERF & Perfecto \\
\hline
\end{tabular}




$\begin{array}{ll}\text { Proc } & \text { Process } \\ \text { PRS } & \text { Presente } \\ \text { PST } & \text { Pasado } \\ \text { PTC } & \text { Participio } \\ \text { PV } & \text { Patient Voice } \\ \text { Res } & \text { Result } \\ \text { S } & \text { Ser } \\ \text { SD } & \text { Sintagma Determinante } \\ \text { SG } & \text { Singular } \\ \text { SL } & \text { Stage Level } \\ \text { T } & \text { Tiempo } \\ \text { U-PPrts } & \text { Unbound Participles } \\ \text { V } & \text { Verbo }\end{array}$




\section{Bibliografía}

Arche, Maria J. y Rafael Marín (2014), “Argument structure and aspect in adjectives and participles: Where are we?”, en Lingua, núm. 149, pp. 95-117.

Bassols de Climent, Mariano (2015 [1956]), Sintaxis latina, Barcelona, Publicacions i Edicions de la Universitat de Barcelona.

Belletti, A. (2017), “(Past) Participle Agreement”, en The Wiley Blackwell Companion to Syntax, segunda edición, pp. 1-29.

Bhatt, Rajesh y Roumyana Pancheva (2005), “Aspect: an overview”, notas 1, 2 y 3 del curso The syntax and semantics of aspect, verano, Linguistic Society of America Institute, 130.

Borer, H. (2015), "The category of roots", en Alexiadou, A., H. Borer and F. Schaffer (eds.), The Roots of Syntax, the Syntax of Root, Oxford, Oxford University Press.

Bosque, Ignacio y Violeta Demonte (dirs.) (1999), Gramática descriptiva de la lengua española, tomos I y II, Madrid, Espasa.

Bosque, Ignacio (2014), “On resultative past participles in Spanish”, en Catalan Journal of Linguistics, núm. 13, pp. 41-77.

Brucart, José Ma. (1990), “Pasividad y atribución en español: un análisis generativo”, en Violeta Demonte y Beatriz Garza Cuarón (eds.), Estudios de lingüística de España y México, El Colegio de México/Instituto de Investigaciones Filológicas, Universidad Nacional Autónoma de México, [https://www.jstor.org/stable/j.ctv43vs5t.10].

Conti Jiménez, Carmen (2004), “Construcciones pasivas con estar”, en ELUA, núm. 18, pp. $21-44$. 
Corver, Norbert y Jairo Nunes (2007), "From trace theory to copy theory”, en The Copy Theory of Movement, Ámsterdam/Filadelfia, John Benjamins, pp. 1-9.

Cuervo, M. C. (2003), "Datives at large", tesis de doctorado en Lingüística, Cambridge MA, The Massachussetts Institute of Technology.

Demonte, V. (2003), “Qué es sintáctico y qué es léxico en la interfaz entre sintaxis y léxico-semántica: Hipótesis y conjeturas”, Universidad Autónoma de Madrid, versión online, formato PDF.

Embick, David (2004), “On the structure of resultative participles in English”, en Linguistic Enquiry, núm. 3, vol. 35, pp. 355-392.

Gallego, Ángel J. y Juan Uriagereka (2009), “Estar = Ser + P”, ponencia presentada en XIX Colloquium on Generative Grammar, abril 1-3, 2009, Universidad del País Vasco, Vitoria-Gasteiz, obtenido de [filcat.uab.cat/clt/membres/professors/gallego/pdf/GALUR_Vitoria2.0.pdf].

Gehrke, Berit y Cristina Marco (2014), "Different by-phrases with adjectival and verbal passives: evidence from Spanish corpus data”, en Lingua, núm. 149, pp. 188-214.

Gumiel-Molina, Silvia, Norberto Moreno-Quibén e Isabel Pérez-Jiménez (2015), “The inference of temporal persistence and the individual/stage-level distinction. The case of ser and estar in Spanish", en Pérez Jiménez, Isabel, Manuel Leonetti y Silvia Gumiel Molina (eds.), New perspectives on the study of Ser and Estar, Holanda, John Benjamins (Issues in Hispanic and Lusophone linguistics, vol. 5), pp. $119-146$.

Harley, Heidi (2011), “A Minimalist Approach to Argument Structure”, en Cedric Boeckx, The Oxford Handbook of Linguistic Minimalism, Oxford/Nueva York, Oxford University Press. 
Higginbotham, James (2000), “On events in linguistic semantics”, en James Higginbotham, Fabio Pianesi y Achille C. Varzi, Speaking of events, Nueva York, Oxford University Press, pp. 49-80.

Jurado, Marta (2000), "Las construcciones pasivas con ser y estar", en Revista Española de Lingüística Española, volumen monográfico, pp. 175-191.

Kratzer, Angelika (2000), “Building statives”, ponencia, Berkeley Linguistic Society.

Kratzer, Angelika (2004), "Building resultatives", en Claudia Maienborn y DiscouAngelika Wöllstein-Leisten (eds.), Event Arguments in Syntax, Semantics, and Discourse, Tübingen, Niemeyer.

Lema Labadie, J. (2018), "Viewpoint Aspect Decomposition in Spanish. Finite and NonFinite Contexts", manuscrito.

Lema Labadie, J. (1992), “Tiempo y aspecto, correlatos sintácticos y semánticos: los auxiliares ser y estar”, en J. A. Pascual (ed.), Estudios Lingüísticos de México y España, Salamanca, Universidad de Salamanca.

Leonetti, Manuel, Isabel Pérez Jiménez y Silvia Gumiel Molina (2015), “Ser and estar. Outstanding questions", en Isabel Pérez Jiménez, Manuel Leonetti y Silvia Gumiel Molina (eds.), New perspectives on the study of Ser and Estar, Holanda, John Benjamins (Issues in Hispanic and Lusophone linguistics, vol. 5), pp. 1-20.

Luján, Marta (1981), “The Spanish copulas as aspectual indicators”, en Lingua, núm. 54, pp. $165-210$.

Mittwoch, A. (2008), "The English Resultative Perfect and Its Relationship to the Experiential Perfect and the Simple Past Tense", en Linguistics and Philosophy, vol. 31, núm. 3, pp. 323-351 
Ramchand, Gillian C. (2007), Verb Meaning and the Lexicon: A First Phase Syntax, borrador obtenido de [http://ling.auf.net/lingbuzz/000307/current.pdf].

Rodríguez-Espiñeira, María José y Jesús Peña (2011), "El contraste aspectual entre infinitivo y participio como predicados secundarios", en M. Victoria Escandell Vidal, Manuel Leonetti y Cristina Sánchez López (eds.), 60 problemas de gramática, Madrid, AKAL.

Taraldsen, Tarald (2015), “On by-passive and why unaccusatives don’t passivize”, en Á. Gallego y D. Ott (eds.), 50 Years Later: Reflections on Chomsky's Aspects, Cambridge, MA, The MIT Press.

Wälchli Bernhard y Bruno Olsson (2012), "Exploring the cross-linguistic relationship between resultative constructions and participles", ponencia presentada en 45th Annual Meeting of the Societas Linguistica Europaea, Estocolmo, obtenido de [http://www.ling.su.se/polopoly_fs/1.104256.1350040176!/menu/standard/file/SLEresultative-waelchli-olsson.pdf].

Zagona, Karen (2015), “Location and the Estar/Ser Alternation”, en Isabel Pérez Jiménez, Manuel Leonetti y Silvia Gumiel Molina (eds.), New perspectives on the study of Ser and Estar, Holanda, John Benjamins (Issues in Hispanic and Lusophone linguistics, vol. 5), pp. 147- 172. 


\section{Anexo}

\section{Lista de verbos con las cuatro lecturas}

Presento en orden alfabético una lista (no exhaustiva) de verbos que pueden aparecer en una pasiva perifrástica, una resultativa estativa, una adjetival con ser y con estar.

Achatado

Adecuado

Agradecido

Alargado

Alocado

Animado

Apagado

Apretado

Callado

Calmado

Centrado

Complicado

Confiado

Desesperado

Distraído

Divertido

Educado

Elevado 
Enfurecido

Enredado

Entretenido

Equivocado

Informado

Interesado

Leído

Limitado

Malcriado

Obstinado

Organizado

Reducido

Sentido

Ejemplos

\section{Pasiva eventiva}

El niño fue calmado con la promesa de un regalo de Reyes.

El director ha sido informado acerca de lo sucedido.

El evento fue organizado por estudiantes.

Los niños son entretenidos con el perro, mientras sus padres salen de la casa.

\section{Resultativa estativa}

Este hombre (ya) está calmado, ahora podemos explicarle todo. 
Todos los profesores que no fueron a la junta (ya) están informados acerca de los puntos tratados.

Todas mis ideas (ya) están organizadas, así que ya me puedo poner a escribir la tesis.

Como el niño (ya) está entretenido, ya podemos ponernos a platicar y no nos interrumpirá.

\section{Adjetival con ser}

Mi sobrino es calmado y siempre lo ha sido, desde bebé.

Este hombre es informado. Siempre sabe mucho.

María siempre ha sido organizada, desde pequeña.

Esta revista es entretenida. La he coleccionado desde el primer número.

\section{Adjetival con estar}

El pequeño está calmado hoy, normalmente es un torbellino.

En su trabajo, Pedro está informado, pero en su casa nunca sabe nada.

Mi mente está organizada, pero mi corazón es un desastre.

El programa de hoy está entretenido, pero generalmente es pésimo. 
EL PARTICIPIO EN

CONSTRUCCIONES PASIVAS Y

RESULTATIVAS DEL ESPAÑOL.
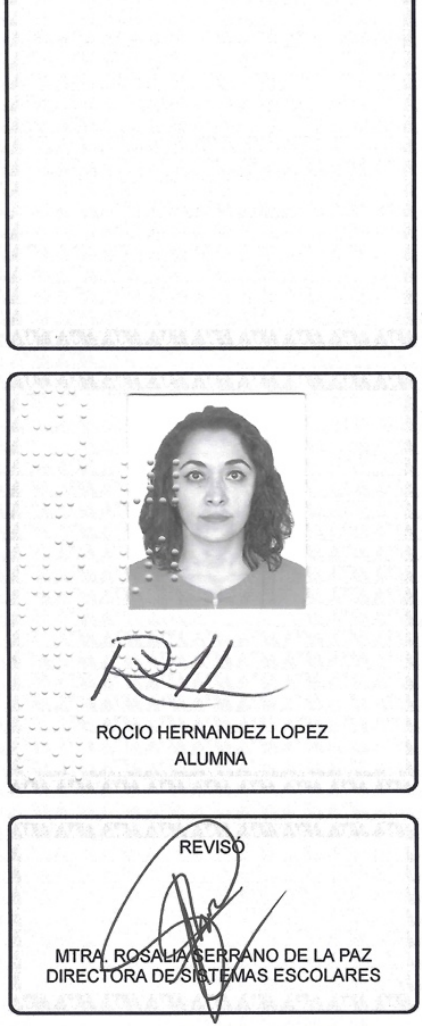

Bajo la Presidencia del primero y con carácter de Secretaria la última, se reunieron para proceder al Examen de Grado cuya denominación aparece al margen, para la obtención del grado de:

MAESTRA EN HUMANIDADES (LINGUISTICA)

DE: ROCIO HERNANDEZ LOPEZ

y de acuerdo con el artículo 78 fracción III del Reglamento de Estudios Superiores de la Universidad 'Autónoma Metropolitana, los miembros del jurado resolvieron:

\section{APROBAR}

Acto continuo, el presidente del jurado comunicó a 1 interesada el resultado de la evaluación $y$, en caso aprobatorio, le fue tomada la protesta.
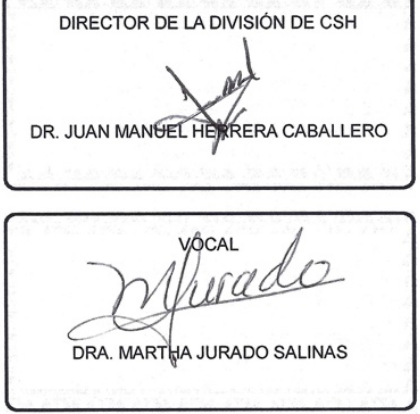
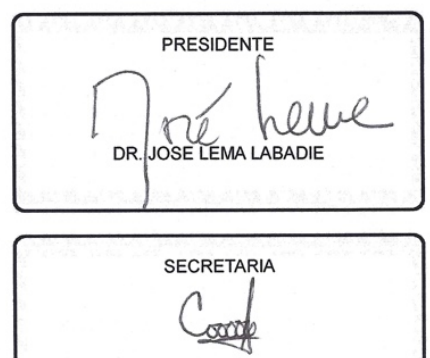

DRA. MA. DEL REFUGIO PEREZ PAREDES 